\title{
PREEMPTIVE ENTRY AND TECHNOLOGY DIFFUSION: THE MARKET FOR DRIVE-IN THEATERS
}

\author{
Ricard Gil \\ Jean-François Houde \\ Shilong Sun \\ Yuya Takahashi \\ Working Paper 29408 \\ http://www.nber.org/papers/w29408 \\ NATIONAL BUREAU OF ECONOMIC RESEARCH \\ 1050 Massachusetts Avenue \\ Cambridge, MA 02138 \\ October 2021
}

First version: April 2016. We would like to thank seminar and conference participants at Sogang University, HKUST, University of Pennsylvania, University of Regensburg, IIOC, McGill International Conference on Marketing, the 2017 European Econometric Society Meetings, the Barcelona GSE Summer Forum, the 2019 North American Summer Meetings of the Econometric Society, and the Third Conference on Structural Dynamic Models in Chicago (2019). The usual disclaimer applies.\} The views expressed herein are those of the authors and do not necessarily reflect the views of the National Bureau of Economic Research.

NBER working papers are circulated for discussion and comment purposes. They have not been peer-reviewed or been subject to the review by the NBER Board of Directors that accompanies official NBER publications.

(C) 2021 by Ricard Gil, Jean-François Houde, Shilong Sun, and Yuya Takahashi. All rights reserved. Short sections of text, not to exceed two paragraphs, may be quoted without explicit permission provided that full credit, including $\odot$ notice, is given to the source. 
Preemptive Entry and Technology Diffusion: The Market for Drive-in Theaters

Ricard Gil, Jean-François Houde, Shilong Sun, and Yuya Takahashi

NBER Working Paper No. 29408

October 2021

JEL No. L1,L12,L82

\begin{abstract}
$\underline{\text { ABSTRACT }}$
This paper studies the role and incidence of entry preemption strategic motives on the dynamics of new industries, while providing an empirical test for entry preemption, and quantifying its impact on market structure. The empirical context is the evolution of the U.S. drive-in theater market between 1945 and 1957. We exploit a robust prediction of dynamic entry games to test for preemption incentives: the deterrence effect of entering early is only relevant for firms in markets of intermediate size. Potential entrants in small and large markets face little uncertainty about the actual number of firms that will eventually enter. This leads to a non-monotonic relationship between market size and the probability of observing an early entrant. We find robust empirical support for this prediction using a large cross-section of markets. We then estimate the parameters of a dynamic entry game that matches the reduced-form prediction and quantify the strength of the preemption incentive. Our counterfactual analysis shows that strategic motives can increase the number of early entrants by as much as 50 percent in mid-size markets without affecting the number of firms in the long run. By causing firms to enter the market too early, we show that strategic entry preemption leads on average to a $5 \%$ increase in entry costs and a $1 \%$ decrease in firms' expected value (relative to an environment without strategic investments).

Ricard Gil

Smith School of Business

Queen's University

Kingston, ON K7M6W4

Canada

ricard.gil@queensu.ca

Jean-François Houde

Department of Economics

University of Wisconsin-Madison

1180 Observatory Dr

Madison, WI 53706

and NBER

Shilong Sun

University of Wisconsin-Madison

1180 Observatory Drive

Madison, WI 53706

ssun226@wisc.edu

Yuya Takahashi

Department of Economics

University of Washington

305 Savery Hall

Box 353330

Seattle, WA 98195

ytakahas@uw.edu
\end{abstract}

houde@wisc.edu 


\section{Introduction}

A central topic in Industrial Organization is the study of the role and incidence of strategic investments. It is now well known that, in strategic environments, a firm's behavior may deviate from what the stand-alone incentive suggests as optimal, if it can affect its rivals' behavior and enhance its strategic position (Fudenberg and Tirole, 1985; Bulow et al., 1985). While understanding the gains from strategic behavior is fundamental for firms and agents operating in strategic environments, policy makers and government antitrust agencies heavily rely on their capacity to identify anticompetitive strategic behavior before it occurs, and identify it when it takes place. Strategic investments induce two types of inefficiencies. First, strategic investments may lead markets to be less competitive, and increase market concentration. Second, strategic investments can induce a mis-allocation of resources by incentivizing firms to over-invest in order to maintain their dominance position. This is an importance concern for the diffusion of new technologies, such as the one we are studying in this paper. In order to deter entry from rivals, firms can be tempted to introduce new products to the market too early, or pay excessive entry costs. Strategic behavior may take many different shapes and forms such as excess capacity (Lieberman, 1987), product proliferation (Chevalier, 1995), networks (Fudenberg and Tirole, 2003; Calzada and Valletti, 2008), advertising (Schmalensee, 1983; Ellison and Ellison, 2011), and learning-by-doing (Benkard, 2004). ${ }^{1}$.

In this paper we study the decision to enter early in a new market as a tool for firms to preempt future entry and limit competition (Dafny, 2005; Schmidt-Dengler, 2006). We contribute to the existing literature by studying empirically how entry deterrence motives affected the diffusion of drive-in movie theaters in the U.S.. Drive-in theaters were a newly commercialized technology in the early 1940s, and diffused broadly and rapidly in the U.S. over the following 10 years. When anticipating this rapid growth, forward-looking firms may have aimed to deter the entry of future competitors by entering the market at an early date.

Measuring the importance of this deterrence motive represents a substantial identification challenge because strategic investments and behavior respond to a latent threat of entry that is, by definition, unobserved. Therefore, the researcher cannot separate straightforwardly those cases without latent threat and those when entry deterrence is successful. Most im-

\footnotetext{
${ }^{1}$ These examples of behavior are important in business activity, and consequently, there is an extensive theoretical literature on strategic entry deterrence (Salop, 1979; Bernheim, 1984; Chang, 1993; Waldman, 1987; Gilbert and Vives, 1986)
} 
portantly, if economists do not observe firms' costs nor profits, it is hard to estimate the optimal behavior that would take place if such deterrence and preemptive incentives were absent. Because of this, empirical evidence supporting existing theories and their implications is scarce.

We get around this identification problem by building on the insights of Ellison and Ellison (2011). In short, Ellison and Ellison (2011) show that when an incumbent faces a threat of entry, the likelihood of further capacity investment depends non-monotonically on market size. If the market is too small, entry is not attractive for potential entrants, so the incumbent does not need to invest further. Alternatively, when the market is too large, the incumbent would not be able to block entry. Only in "intermediate-size" markets, the incumbent can deter entry by expanding capacity. Thus, investment capacity by the incumbent is non-monotonic in market size.

We show that this insight is valid in a game of entry preemption. We illustrate this first with a simple two-period duopoly model of strategic entry where no firm has a stand-alone incentive to enter early. This simple framework easily shows that there exists a non-monotonic relationship between market size and the probability of early entry. We then generalize this two-period framework by estimating a dynamic game with stochastic entry and technological progress. We use this model to quantify the effect of entry preemption on firm profits and entry costs.

A key challenge when implementing this identification strategy is to find a relevant and exogenous measure of market size that does not directly impact the cost of entering a new market, or the variable profit. Ellison and Ellison (2011), for instance, use firms' revenue prior to the expiration of a patent as a proxy for market size, which arguably affects both market size and variable profits. In the case of seasonal activities like drive-in theater, the "size" of the market is affected both by the number and characteristics of potential consumers, but also by the number of days a theater can operate. In our empirical application we use the percentage of days with warm weather in a county as a measure of market size. The rational is that inclement weather causes drive-in theaters to shut down, especially given the capabilities of automobiles in the 1950s. In addition, since theaters involved specific investments, the land cannot easily be used to generate other revenue in the off-season, implying that everything else being equal theaters in the north are less profitable than in the south. Crucially, this 
variable affects the potential revenue of a theater (through the number of potential active days), but does not directly impact the willingness-to-pay or cost of operating. We illustrate this by showing that the data exhibit enough variation across markets in average temperature to identify the effect of market-size on entry separately from other measures of profitability.

We find robust empirical evidence for our prediction in entry patterns of drive-in theaters across counties in the U.S. between 1945 and 1957. In particular, we show that the probability of entering the market before 1950 is a non-monotonic function of the fraction of warm days. This result is robust to alternative measures of preemption, as well as the inclusion of a rich set of control variables. We also find that the long-run number of theaters is strictly increasing in the number of warm days, consistent with the idea that the number of warm days strictly increase firms profitability.

We then generalize our two-period entry model to capture several important features that characterize the diffusion of new technologies. In particular, we estimate a stochastic industry dynamics game in which variable profits and entry cost improve over time in a predictable manner; for instance due to improvements in the quality of the product (e.g. availability of movies and sound/picture quality), or reduction in the sunk cost of acquiring the equipment. This leads to a non-stationary markov-perfect entry game that we estimate by Maximum Likelihood using a nested-fixed point algorithm. In addition to quantifying the effect of competition on profits (i.e. deterrence incentive), the model allows us to identify the rate of technological progress in the industry, while accounting for unobserved market heterogeneity. We show that failing to account of unobserved heterogeneity biases downward the rate at which variable profits (e.g. quality) and fixed-cost change over time.

Using the estimated parameters, we quantify the magnitude of the preemption incentive by analyzing a counter-factual environment in which firms can commit to specific entry strategies (as opposed to using markov-perfect strategies). We find that strategic entry preemptive motives increase the number of early entrants by as much as 50 percent in mid-size markets without having an effect on the overall number of entrants. In our model and empirical setting, this means that early strategic entry does not change the number of operating firms in a market in the long run, it just shifts entry to earlier periods where firms in the absence of strategic incentives would have deemed entry to be not optimal. Consequently, our counterfactual exercises can separate the impact of strategic motives on entry costs and the present discounted 
value of firms. We find that strategic entry preemption lowers firms expected profits relative to an environment in which firms could commit to a specific entry strategy (Fudenberg and Tirole, 1985), but this effect is overall small. In contrast, the effect of strategic preemption on the overall entry cost incurred by firms is economically large. In mid-size markets where the incentive to enter early is the strongest, firms incur entry costs that are $5 \%$ higher on average.

Our paper builds on and contributes to the strategic behavior literature of mainly theoretical flavor (Salop, 1979; Bernheim, 1984; Chang, 1993; Waldman, 1987; Gilbert and Vives, 1986). While the corresponding empirical literature is far less abundant, others have examined strategic incentives of incumbents in other contexts such as hospitals (Dafny, 2005); restaurants (Igami and Yang, 2016; Fang and Yang, 2021); transportation and airlines (Goolsbee and Syverson, 2008; Gil and Kim, 2021); supermarkets (West, 1981; Cotterill and Haller, 1992); technology adoption in healthcare (Schmidt-Dengler, 2006); pharmaceutical industry (Hünermund et al., 2014); telecommunications (Goldfarb and Xiao, 2011; Seamans, 2012); and entertainment (Takahashi, 2015).

Our paper is closest to Ellison and Ellison (2011) on strategic R\&D and advertising investments in the pharmaceutical industry, Schmidt-Dengler (2006) in MRI adoption, and Igami and Yang (2016) and Fang and Yang (2021) on entry of fast-food restaurants. Our paper contributes to this literature in a number of ways. First, we build on the insights of Ellison and Ellison (2011) on how to test for strategic preemptive entry, and we improve their test by using an exogenous measure of market size, namely, the share of good weather days in a year. We use this exogenous variation to identify the parameters of a dynamic entry game entry preemption in a transparent way. Third, following Schmidt-Dengler (2006), our model and counter-factual analysis explicitly accounts for the non-stationary transition of the industry by modelling technological progress as a predictable diffusion process. In contrast, Igami and Yang (2016) and Fang and Yang (2021) use an infinite horizon markov-perfect industry equilibrium model similar to Aguirregabiria and Mira (2007) to study the entry/exit of firms. The advantage of our approach is that the model generates a unique markov-perfect equilibrium; which allows us to account for technological process and unobserved heterogeneity when estimating the structural parameters and performing our counter-factual analysis. The existence and uniqueness of MPE follow from the single-direction markov transition property 
described in Doraszelski and Judd (2012).

The rest of the paper is organized as follows. In Section 2, we first detail the birth and background of the U.S. drive-in theater industry, and describe the data for our empirical analysis. Section 3 develops a simple entry game and shows by simulation that even a simple model can generate the non-monotonicity observed in the data. In Section 3, we also show reduced-form evidence of preemptive entry through non-monotonicity of the relation between market size and probability of early entry. In Section 4, we generalize the framework in Section 3 and structurally estimate the parameters of the model. Section 5 performs several counterfactual analyses to shed light on the mechanisms underlying the impact of strategic entry preemption motives on market structure. Section 6 concludes.

\section{Institutional Detail and Data Description}

\subsection{The industry}

The first ever known drive-in opened its doors to the public in 1921 in Comanche, Texas, when Claude Caver obtained a public permit to project silent films downtown to be viewed from cars parked bumper to bumper. Following this and similar experiments in Texas, it was Richard Hollingshead from Camden, New Jersey, who applied for a drive-in patent on August 6, 1932, and consequently given U.S. Patent 1909537 on May 16, 1933. Hollingshead's drive-in opened on Admiral Wilson Boulevard in Pennsauken, New Jersey, on June 6, 1933, offering 400 slots and a 40 by 50 feet (12 by 15 meter) screen. Although Hollingshead's drive-in only operated for three years, the business concept caught on in New Jersey and other states such as Pennsylvania, California, Massachusetts, Ohio, Rhode Island, Florida, Maine, Maryland, Michigan, New York, Texas and Virginia.

A drive-in theater essentially differs from a regular theater in that it consists of a large outdoor movie screen, a projection booth, a concession stand, and a large parking area for cars where customers can view films from the privacy and comfort of their automobiles. The screen can be as simple as a white wall or as complex as a steel truss structure. While drive-in theaters originally provided sound through speakers on their screens, they eventually transition to a sound system of individual speakers for each car in the 1940s and 1950s. This system was not only cheaper but also higher quality technology for broadcasting the movie 
soundtrack for each car. Ultimately, by the 1960s, movie sound was picked up by an AM or FM radio on an often high-fidelity stereo installed in the customers' vehicles.

The drive-in's popularity peaked in the late 1950s and early 1960s, particularly in rural areas, with more than 4,000 drive-in theaters spread across the United States. Its popularity in rural areas should not surprise anybody. Not only did drive-in theaters widen and expand leisure choices in these markets, they also allowed full families to enjoy movies together at a moderate cost. For example, a family with a baby could take care of their child while watching a movie, while teenagers and young adults with access to autos found drive-in theaters ideal for dates. Unfortunately, this business concept also presented a few caveats on the revenue side. Not only was revenue more limited than regular theaters since showings can only begin at twilight, operating a drive-in theater during the winter season in some parts of the U.S. was nearly impossible due to the inclement weather and the technical equipment (namely heating equipment) of the autos during that time. Therefore, because locations with expectations of bad weather were less likely to open their doors to customers regularly, weather conditions imposed exogenous variation in the business profitability across locations in the U.S.

While part of the increase in the number of drive-in theaters is explained by its increase in popularity from the demand side, it is also true that fixed costs of entry steadily decreased over time between 1933 to their final demise in the 1970s. On the one hand, the patent earned by Richard Hollingshead in 1933 was invalidated in 1950 by the Delaware District Court (by the end of its life). On the other hand, better and cheaper technology steadily appeared over time in combination with constant learning-by-doing that industry practitioners easily transmitted across contemporaneous and future exhibitors. In the end, it is straightforward to conclude that entry costs went down over time in the drive-in theatrical industry.

Finally, as a result of the increase in competition from home entertainment (color television and VCRs), the 1970s oil crisis and wide adoption of daylight saving time as well as the 1980s real estate interest rate hikes, attendance to movie theaters declined sharply and made it harder for drive-ins to operate profitably. By the late 1980s, less than two hundred drive-ins were in operation in the U.S. and Canada. Only recently, drive-in theaters have lapsed into a quasi-novelty status, and by 2013, 389 drive-in theaters were in operation across the U.S. This represents a meager 1.5 percent of all movie screens in the United States, relative to the industry's heyday in the early 1960s with 25 percent of the nation's movie screens had been 
in a drive-in theater.

\subsection{The data}

Our data come from the yearly issues of the Movie Yearbook between 1945 and 1957. This Yearbook published annually a de facto census of theaters in the U.S. as well as a directory of U.S. theatrical firms with four or more theaters (Gil, 2015; Takahashi, 2015). Importantly for our purposes, the Movie Yearbook also contained a listing of all drive-in theaters by city and state under separate cover (see Figure 1). Because most theaters from these data no longer exist, or were located in cities or towns that are no longer independent municipalities, we complemented the data with information from www.cinematreasures.org when necessary. The information on this site allowed us to find the approximate location of theaters and check whether changes in theater names may have occurred during the sample period.

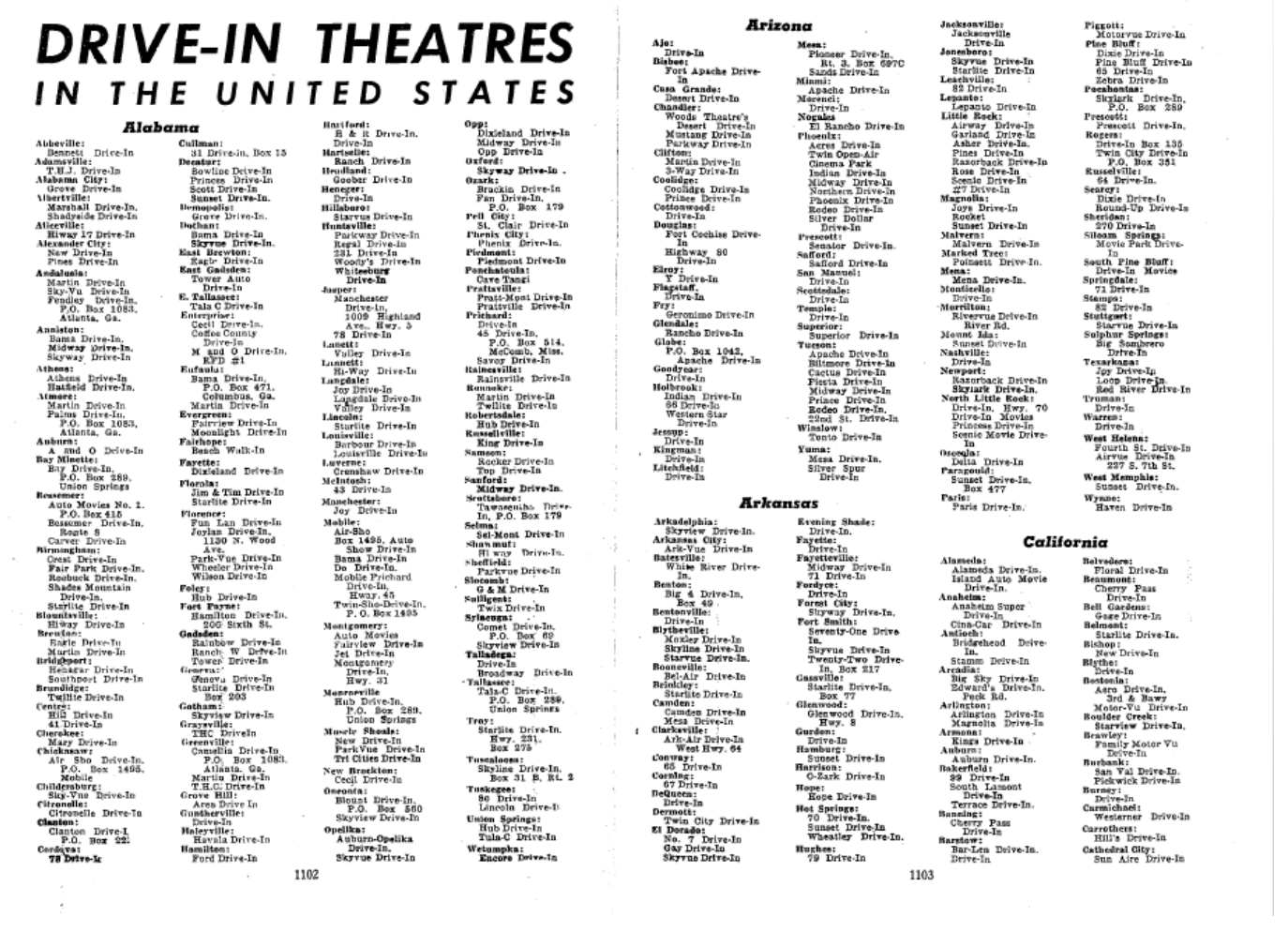

Figure 1: Data example: Movie yearbook

We complement these data with county-level data from the "County and City Data Book" from 1947 to 1960, and county-level weather data from NOAA Satellite and Information Service. The resulting data consists of 2193 county data points per year if we count only those counties that observed entry between 1945 and 1957, and a total of 2911 county data 
points if we include all counties with demographic and weather data available and yet no drive-in theater entry. Thus, in our data 718 counties out of a total of 2911 never observe entry of drive-in theaters and therefore do not contribute to explaining the observed variation in the number of drive-in theaters, entry and exit rates.

In our reduced-form analysis below, we reduce even further the scope of our data to those counties that only observe entry of one or two drive-in theaters during the period 1945-1957. That restriction leaves us with a total of 1272 counties which we use in our reduced-form empirical analysis. Limiting our sample in the reduced-form analysis is important because we want to capture the strategic interaction between players and the corresponding nonmonotonicity across those markets that are bounded to have a maximum of two drive-in theaters given their market and potential profitability characteristics.

Table 1 provides summary statistics for all four data samples. The first sample is composed of the full cross-section of 2911 counties. This sample includes all counties with demographic and weather data regardless of whether they experienced drive-in movie theater entry during the 1945-1957 period. Our dependent variables are dummy variables for whether a county experienced entry before 1950, before 1951, or between $1950 \& 1955$, and the number of years within our sample that the county lasts to experience entry (a combination of the information of the former two dummies). As we show in the far left column of Table 1, 19.9\% of counties in our full sample experience entry prior to 1950 and almost $69 \%$ of counties experience entry between 1950 and 1955. Note the values of these variables are different for the sample of 2193 counties that experienced any entry (26.5\% early entry and 5.3 years before entry), and the sample of 1272 counties that experience entry of one or two theaters only $(8.5 \%$ early entry and 6.1 years before entry).

Table 1 also shows summary statistics of our measures of county "market" size, mainly weather variables. While population is widely used to measure market size, in our context it does not provide a complete picture of the potential number of clients per year. Population affects economic activities in many different ways; it will affect the number of customers, which is directly related to market size; however, it could also affect firm entry and labor costs. Therefore, in our empirical analysis, population is a factor that we control for. In our context, weather variables may be a more direct and transparent measure of market size. Because drive-in theaters were set outdoors, weather affected its actual appeal to consumers. 
Even if a county has large population, the effective market size may be small under a long and severe winter. For that reason, we bring into our analysis the frequency of warm days (above 25 degree Celsius). Table 1 shows that the average county in our full sample had 33\% warm days, and $34 \%$ in our reduced samples.

Table 1: Summary statistics

\begin{tabular}{|c|c|c|c|c|c|c|c|c|}
\hline \multirow{3}{*}{ No. Obs } & \multirow{2}{*}{\multicolumn{2}{|c|}{$\begin{array}{c}\text { All markets } \\
2911\end{array}$}} & \multirow{2}{*}{\multicolumn{2}{|c|}{$\begin{array}{c}\text { N_\{max }\}>0 \\
2193\end{array}$}} & \multirow{2}{*}{\multicolumn{2}{|c|}{$\begin{array}{c}\mathbf{N} \_\{\max \}=\mathbf{0 , 1 , 2} \\
1990\end{array}$}} & \multirow{2}{*}{\multicolumn{2}{|c|}{$\begin{array}{c}\text { N_ }\{\max \}=1,2 \\
1272\end{array}$}} \\
\hline & & & & & & & & \\
\hline & Mean & Range & Mean & Range & Mean & Range & Mean & Range \\
\hline Entry Before 1950 & 0.199 & {$[0,1]$} & 0.265 & {$[0,1]$} & 0.054 & {$[0,1]$} & 0.085 & {$[0,1]$} \\
\hline Entry Before 1951 & 0.370 & {$[0,1]$} & 0.492 & {$[0,1]$} & 0.177 & {$[0,1]$} & 0.277 & {$[0,1]$} \\
\hline Years Before Entry & - & - & 5.340 & {$[0,10]$} & - & - & 6.059 & {$[0,10]$} \\
\hline Entry Btw 1950-1955 & 0.689 & {$[0,1]$} & 0.915 & {$[0,1]$} & 0.554 & {$[0,1]$} & 0.867 & {$[0,1]$} \\
\hline Freq Warm Days & 0.330 & {$[0.057,0.807]$} & 0.336 & {$[0.057,0.807]$} & 0.327 & {$[0.061,0.782]$} & 0.336 & {$[0.061,0.782]$} \\
\hline Population (millions) & 0.049 & {$[0.001,4.508]$} & 0.061 & {$[0.002,4.508]$} & 0.021 & {$[0.001,2.738]$} & 0.025 & {$[0.002,2.738]$} \\
\hline Median Income & 0.509 & {$[0,0.9]$} & 0.522 & {$[0,0.9]$} & 0.479 & {$[0,0.9]$} & 0.486 & {$[0,0.9]$} \\
\hline Pop Growth & 0.036 & {$[-0.474,1.549]$} & 0.067 & {$[-0.400,1.549]$} & -0.013 & {$[-0.474,1.095]$} & 0.011 & {$[-0.378,1.095]$} \\
\hline \# of indoor theaters & 5.471 & {$[0,274]$} & 6.430 & {$[0,274]$} & 3.211 & {$[0,143]$} & 3.589 & {$[0,143]$} \\
\hline tv rate & 0.558 & {$[0.002,1.000]$} & 0.586 & {$[0.002,1.000]$} & 0.507 & {$[0.002,1.000]$} & 0.529 & {$[0.002,1.000]$} \\
\hline motorization & 0.739 & {$[0.000,1.614]$} & 0.728 & {$[0.118,1.379]$} & 0.745 & {$[0.000,1.614]$} & 0.730 & {$[0.118,1.379]$} \\
\hline Urban Pop Share & 0.288 & {$[0,1]$} & 0.358 & {$[0,1]$} & 0.2 & {$[0,1]$} & 0.270 & {$[0,1]$} \\
\hline Employment Share & 0.955 & {$[0.350,0.999]$} & 0.951 & {$[0.350,0.996]$} & 0.961 & {$[0.509,0.999]$} & 0.958 & {$[0.509,0.996]$} \\
\hline College Share & 0.058 & {$[0.011,0.223]$} & 0.060 & {$[0.014,0.218]$} & 0.054 & {$[0.011,0.223]$} & 0.056 & {$[0.014,0.218]$} \\
\hline Share of Adults & 0.605 & {$[0.431,0.769]$} & 0.607 & {$[0.440,0.769]$} & 0.599 & {$[0.431,0.716]$} & 0.600 & {$[0.446,0.712]$} \\
\hline Share of Black & 0.098 & {$[0,0.843]$} & 0.101 & {$[0,0.843]$} & 0.097 & {$[0,0.843]$} & 0.100 & {$[0,0.843]$} \\
\hline Pop Density (K/miles $\left.{ }^{2}\right)$ & 0.164 & {$[0.0001,89.095]$} & 0.205 & {$[0.0005,89.095]$} & 0.083 & {$[0.0001,36.028]$} & 0.107 & {$[0.0005,36.028]$} \\
\hline Farm Value (million \$) & 0.007 & {$[0,0.157]$} & 0.008 & {$[0,0.157]$} & 0.006 & {$[0,0.052]$} & 0.006 & {$[0.000,0.052]$} \\
\hline
\end{tabular}

Note: This table provides summary statistics of all variables used in our empirical analysis for different samples conditioning on maximum number of entrants in a market.

We also use other controls such as median family income, urban population share, employment share, college share, share of adults, share of black population, population density, and farm value as provided by the county and city data set. We include these variables to control for differences across cities that our measures of market size cannot capture, and that may drive the potential profitability of entry of a drive-in theater during our sample period. For example, because of the existing correlation in the U.S. between temperature and poverty, not controlling for income in our regressions would definitely bias our results. Table 1 also includes summary statistics for other variables such as the number of indoor theaters at the county level, TV penetration, and motorization rates.

Table 2 describes entry and exit patterns between 1945 and 1957. Because we do not observe data prior to 1945, we take 1945 as a departure point and show the number of counties in the U.S. experiencing net entry and net exit in any given city within their county boundaries, conditional on never having more than two drive-in theaters during our sample 
period. On the one hand, Table 2 shows how net exit is rather rare for all years except for the years between 1953 and 1957 when more counties experienced net exit in some of their cities, but not necessarily within their county boundaries overall. On the other hand, net entry was sparse during the first years of our sample (1946 to 1948) and sped up between 1949 and 1957. Figures 2 and 3 provide consistent graphical evidence of diffusion and adoption. Figure 2 shows a rapid increase in adoption around 1948 that starts stabilizing around 1955. Similarly, Figure 3 shows geographical dispersion in adoption. It is easy to see that most adoption occurred between 1948 and 1950, and that by 1957 almost all counties in the U.S. had experienced entry of at least one drive-in theater.

Table 2: Entry and exit per year

\begin{tabular}{ccc}
\hline & $\begin{array}{c}\text { \# Counties } \\
\text { wear }\end{array}$ & $\begin{array}{c}\text { \# Counties } \\
\text { with Exit }\end{array}$ \\
1946 & 0 & 0 \\
1947 & 5 & 2 \\
1948 & 15 & 0 \\
1949 & 94 & 12 \\
1950 & 268 & 4 \\
1951 & 295 & 7 \\
1952 & 173 & 10 \\
1953 & 254 & 72 \\
1954 & 240 & 218 \\
1955 & 222 & 6 \\
1956 & 319 & 111 \\
1957 & 313 & 247 \\
Total & 1,319 & 535 \\
\hline
\end{tabular}

Note: This table shows the number of counties with net entry and net exit per year in our sample.

In any case, these data are consistent with anecdotal evidence that drive-in theaters spread quite rapidly between the 1940s and 1950s, and slowed down in the 1960s. A cautionary note is due regarding the information on net exit in Table 2. Exit information (drive-in theater disappearing from our data sample) is usually followed by entry. Therefore, exit may be disguised by changes in ownership, renaming or rebranding of existing drive-in theaters. We do our best to attenuate the impact of such noise by matching addresses of exiting and entering drive-in theaters over time. In the next section, we first provide a simple entry game to derive testable predictions regarding non-monotonicity between market size and early strategic entry 


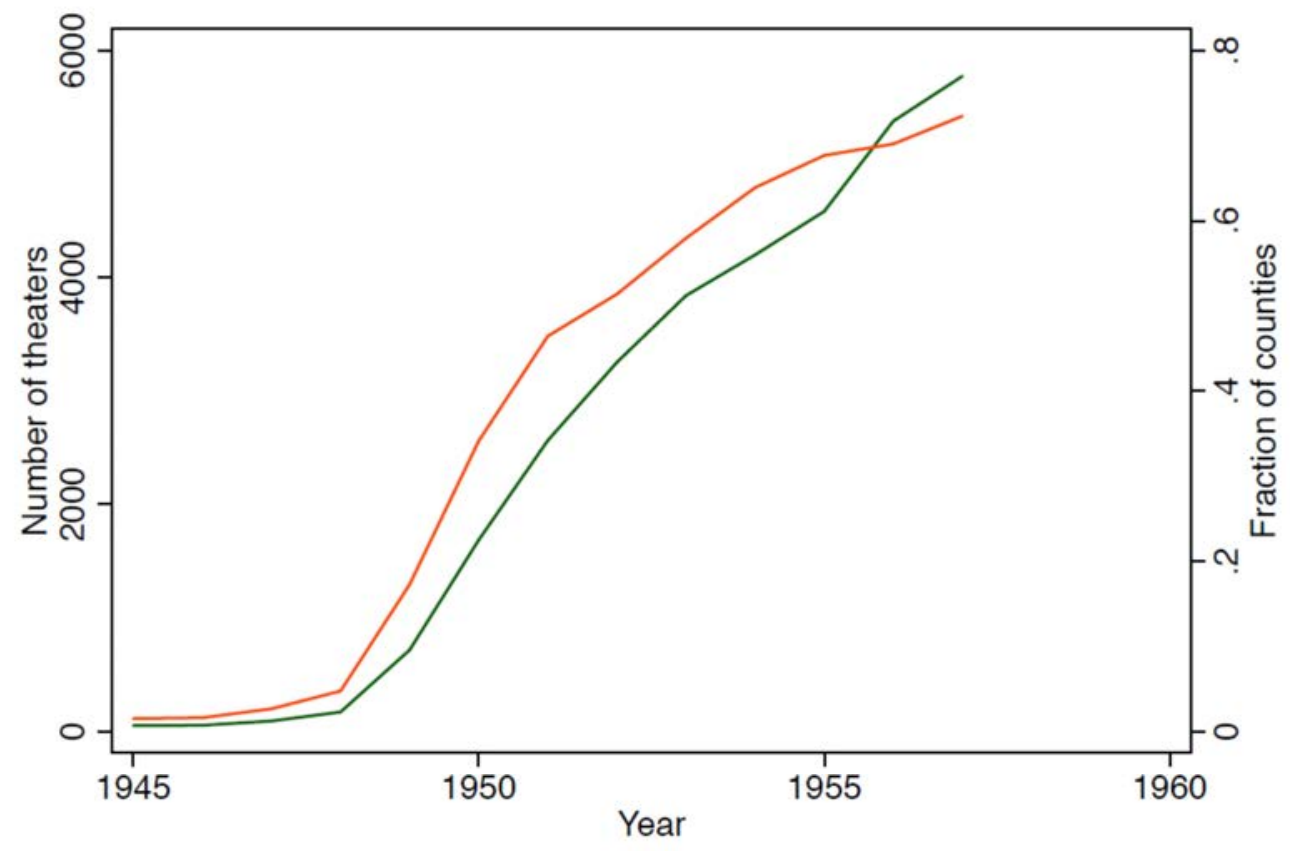

Nubmer of theaters Fraction of counties

Figure 2: Diffusion of drive-in theaters across counties between 1945 and 1957

that we can take to data.

\section{A Simple Model and Reduced-Form Evidence}

\subsection{A simple entry game}

In this section, we provide a simple model of entry with preemption gains that builds on work by Ellison and Ellison (2011). The goal of this simple game is to gain intuition on why the probability of entry in the first period is non-monotonic on the market size. In a world with uncertain but decreasing fixed costs of entry, firms benefit from delaying entry all else equal. Yet, in markets where duopoly profits may not cover entry costs, strategic entry in the first period may decrease the expected gains of entry in the second period. However, the probability of late entry does not depend on whether early entry occurred for very small markets (zero anyway) or large markets (very likely). Thus, the likelihood of early entry in a given market must be non-monotonic in market size. Because in mid-size markets the likelihood of late entry decreases with early entry, gains of early entry increase faster than market size in this intermediate range of market. We proceed next to the setup of the game. 

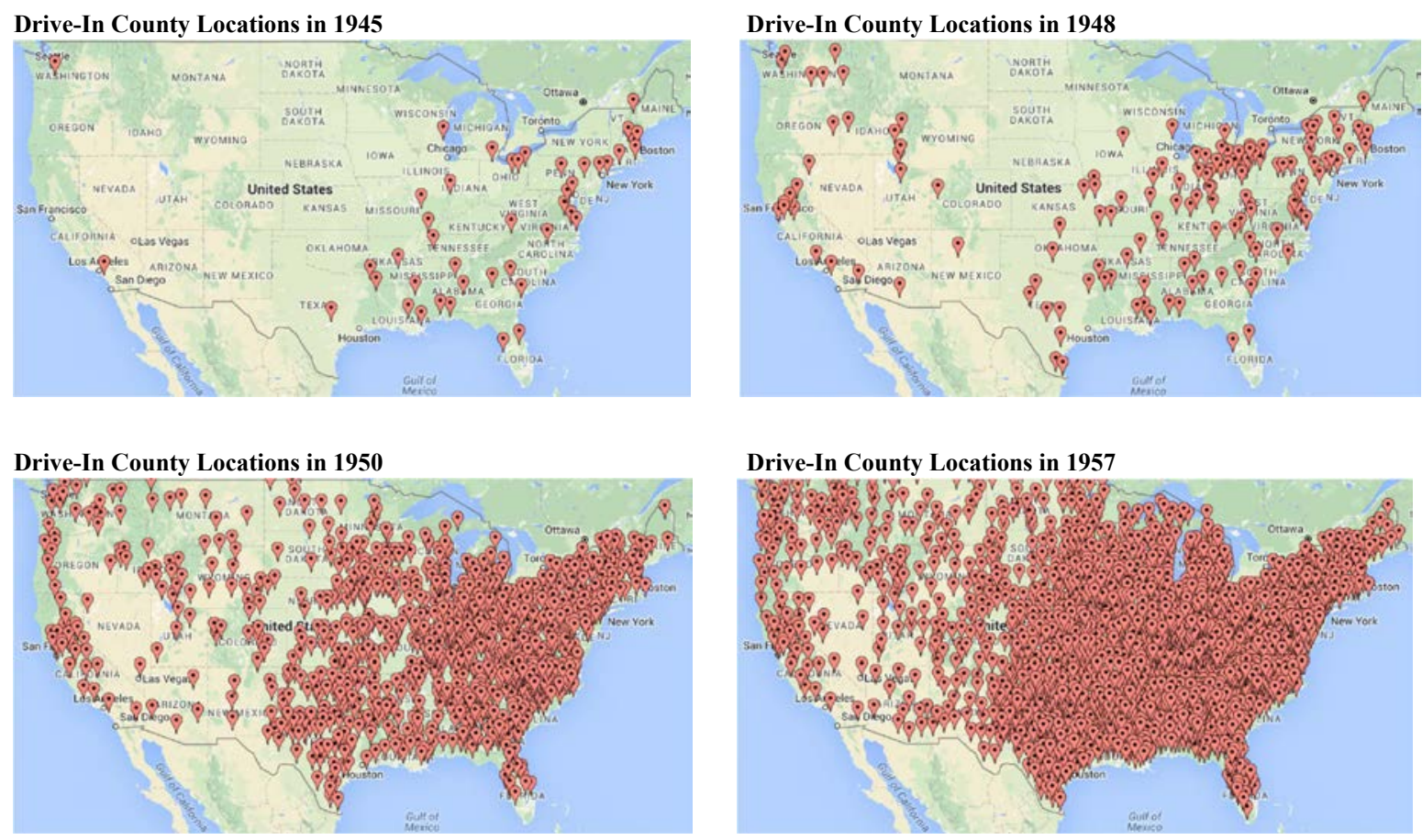

Figure 3: Diffusion graph of drive-in movie theaters at the county level for 1945, 1948, 1950 and 1957

Consider a game of entry with two potential entrants. Time is discrete; $t=1,2 \ldots$ For simplicity, we assume that players can make an entry decision only in these two periods, $t \in 1,2$. Entry is a terminating action so there is no exit. Initially, no player has entered the market. At the beginning of the first period, two players simultaneously decide whether to enter the market or not. Players perfectly observe entry after players' decisions in period 1. In the second period, players who have not entered the market in the previous period decide whether to enter or not. From the third period on, players make no entry decisions and the period payoffs of the two players stay constant. ${ }^{2}$

For the sake of simplicity, we make assumptions on the per-period payoffs and entry costs that grant no stand-alone incentive to early entry. In particular, we assume zero payoffs in the first period and a second-period payoff that depends on the number of entrants and is common across players; the monopoly profit is $M$, while the duopoly profit $D$, with $D<M$. In addition, upon entry, a player incurs one-shot entry cost, $\phi_{t}$. This entry cost $\phi_{t}$ is a common (across players) and deterministic entry cost that satisfies $\phi_{1}=\phi$, and $\phi_{2}=0$. Players

\footnotetext{
${ }^{2}$ The assumption that players do not exit is supported by the observation that in the data, the frequency that exits are observed is very low.
} 
maximize their expected payoff, and we ignore discounting again for simplicity purposes.

In this setting, we solve for the mixed strategy equilibrium under complete information by specifying $\sigma_{t}(k)$ as the probability that a player enters in period $t$ when $k$ players have already entered. We consider three distinct cases: small markets $(D<M<0)$, intermediate size markets $(D<0<M)$, and large markets $(0<D<M)$. The first case of a small market is easy to solve and uninteresting in that $\sigma_{t}=0$ because there is no incentive to enter ever. The third case of large markets is also easy to solve and uninteresting in that $\sigma_{2}(0)=\sigma_{2}(1)=1$. Anticipating the certain entry of competition in the second period, both firms will choose to avoid paying the entry cost $\phi$ and wait for the second period. Hence, we have $\sigma_{1}=0$ because there is no point in rushing into the market in $t=1$.

The interesting case for our purpose of study is the case of intermediate size markets where $D<0<M$. In this scenario, in period $t=2$, it is easy to show that $\sigma_{2}(1)=0$ because no firm would join an incumbent in the second period if $D<0$. Calculating $\sigma_{2}(0)$ is also simple in this context. In equilibrium, $\sigma_{2}(0)$ must be such that the expected payoff of entering in the second period equals the certain payoff of not entering such that,

$$
\sigma_{2}(0) D+\left(1-\sigma_{2}(0)\right) M=0
$$

and therefore,

$$
\sigma_{2}(0)=M /(M-D)
$$

Anticipating this result in $t=1$, the equilibrium $\sigma_{1}$ must be such that the expected payoff of entering in the first period equals the expected payoff of holding off to the second period. This is equivalent to the following expression,

$$
\sigma_{1} D+\left(1-\sigma_{1}\right) M-\phi=\left(1-\sigma_{1}\right)\left[\sigma_{2}(0) D+\left(1-\sigma_{2}(0)\right) M\right]
$$

and as a result,

$$
\sigma_{1}=(M-\phi) /(M-D)
$$

It is then easy to show that $\sigma_{1}$ will be non-monotonic in market size. Take for example 
Figure 4 where we call $x$ market size, and we assume $M=x-0.5, D=x / 3-0.5$, and $\phi=0.3$. Note that the probability of entry in period $1 \sigma_{1}$ is increasing from $x=0.8$ to $x=1.4$, and decreasing from $x=1.4$ to $x=1.5$. See also that the probability of entry in the first period $\sigma_{1}=0$ for smaller and larger markets as predicted. In the next section, we test for the existence of non-monotonicity in the relationship between the probability of early entry and market size using reduced-form evidence.

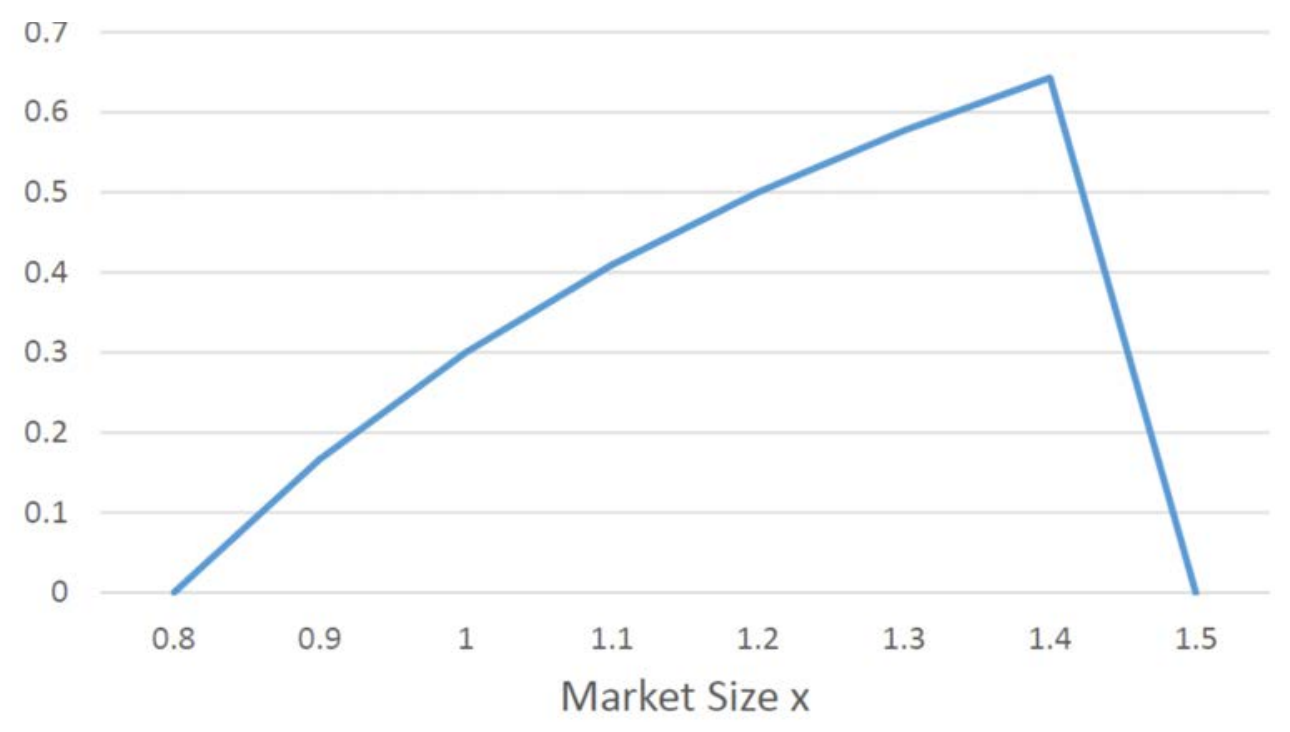

Figure 4: Early entry probability is non-monotonic in market size $x$ (assume $M=x-0.5$, $D=x / 3-0.5, \phi=0.3)$

\subsection{Reduced-form test for entry preemption}

Let us now start our empirical exploration using reduced-form specifications that aim to capture the non-monotonicity in the probability of entry with market size. We do this in two ways. First, we estimate the probability of entry in a given county prior to 1950 subject to market size measured by the frequency of warm days in that county and its square while controlling for all other market characteristics as described in section 2.2. Table 3 reports the estimated coefficients and marginal effects of the Probit regressions. In column 1, we control for market characteristics such as population and squared population, median family income and population density among others. We show frequency of warm days increases the probability of entry but its frequency squared decreases entry. Therefore, the predicted non-monotonicity of market size on the probability of entry as the maximum probability of entry is reached at $41 \%$ frequency of warm days. Figure 5 provides semi-parametric evidence 
of non-monotonicity using the expected probability of entry given by our results in column 1 .

Table 3: Probit regressions of entry prior to 1950 on market size

\begin{tabular}{lcccc}
\hline Prob of Early Entry & \multicolumn{2}{c}{$(\mathbf{1})$} & \multicolumn{2}{c}{$(\mathbf{2})$} \\
& $\mathbf{d F} / \mathbf{d x}$ & $\mathbf{P}$ Val & $\mathbf{d F} / \mathbf{d x}$ & $\mathbf{P ~ V a l}$ \\
Freq Warm Days & 0.844 & 0.003 & & \\
(Freq Warm Days) & -1.028 & 0.01 & & \\
2nd Quartile Freq Warm Days & & & 0.015 & 0.176 \\
3rd Quartile Freq Warm Days & & & 0.078 & 0.000 \\
4th Quartile Freq Warm Days & & & 0.031 & 0.099 \\
POP & 1.937 & 0.000 & 1.981 & 0.000 \\
(POP) & -3.945 & 0.047 & -3.894 & 0.047 \\
Median Income & 0.039 & 0.319 & 0.034 & 0.37 \\
pop growth & 0.032 & 0.159 & 0.036 & 0.093 \\
\# of indoor theaters & -0.002 & 0.284 & -0.002 & 0.241 \\
tv rate & 0.036 & 0.034 & 0.033 & 0.049 \\
motorization & 0.077 & 0.004 & 0.095 & 0.001 \\
Urban Pop Share & 0.005 & 0.814 & 0.007 & 0.723 \\
Employment Share & 0.149 & 0.171 & 0.161 & 0.143 \\
College Share & 0.048 & 0.802 & 0.09 & 0.632 \\
Adult Share & -0.354 & 0.001 & -0.391 & 0.000 \\
Black Share & -0.017 & 0.552 & -0.006 & 0.837 \\
Pop Density & 0.018 & 0.784 & 0.013 & 0.837 \\
Farm Value & -0.968 & 0.129 & -0.735 & 0.246 \\
Sample & $\mathrm{N}\{\{$ max $\}=1,2$ & N_\{max\}=1,2 \\
Observations & 1,272 & 1,272 \\
\hline
\end{tabular}

Notes: Marginal effects reported of probit regressions at the county level for all counties that either had one or two drive-in theaters in our sample. Column (1) uses both population and frequency of warm days. Column (2) uses quartiles of frequency of warm days to measure non-monotonicity between early entry and market size.

A potential concern with the analysis in column 1 of Table 3 is that a linear and quadratic term of market size cannot control for highly non-linear effects of market size that may be correlated with early entry. To control for such potential unobserved heterogeneity, the specification in column 2 of Table 3 divides our sample of counties by quartiles in the frequency of warm days, and runs probit regressions of the probability of entry prior to 1950 on quartile dummies, controlling for differences in other variables across counties such as population, population square, and demographics. Our results in column 2 show non-monotonicity in the three quartile-dummies of frequency of warm days taking counties in the first quartile as the relative group. The second quartile dummy is not statistically different from the relative group of the first quartile. The counties in the third quartile have a statistically significant 


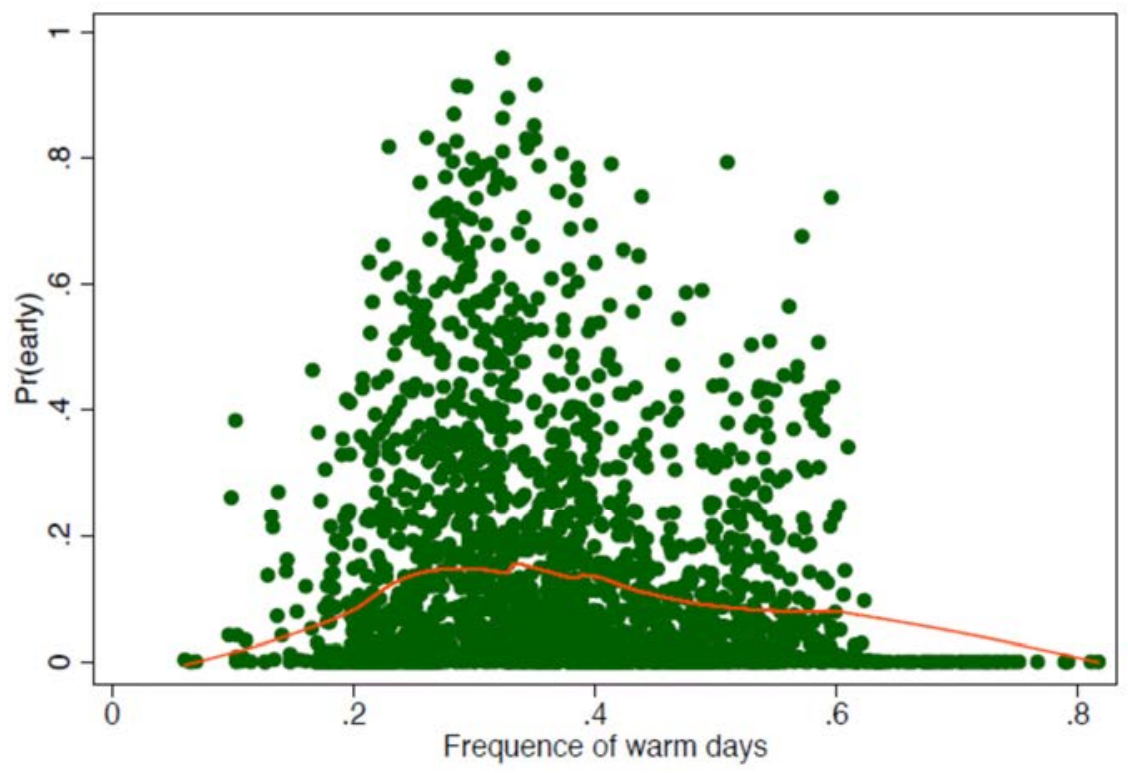

Figure 5: Semi-parametric evidence of non-Monotonicity between early entry and frequency of warm days

higher probability of early entry prior to 1950, and the fourth quartile displays a lower (yet statistically significant) probability relative to the third quartile but higher than the first and second quartiles.

A second way to estimate the non-monotonicity existing between market size and early entry is to construct another dependent variable measuring the number of years observed before entry since 1945 (our first year of data). Once we create this variable, we follow the same strategy as in Table 3 and run OLS regressions that contain frequency of warm days, population and their squared variables as well as other demographic controls also used in Table 3 above. We show the results of this second empirical strategy in Table 4. Our results here are qualitatively the same as those in Table 3. Column 1 shows non-monotonicity in the frequency of warm days while controlling for county demographics. Column 2 shows results of non-monotonicity in the second and third quartile dummies although not statistically significant.

In a nutshell, we find evidence of a non-monotonic relationship between the probability of entry and market size (measured with frequency of warm days) when measuring entry as rates prior to 1950 and number of years before observing entry. This is indicative that market size increases the probability of early entry in "intermediate size" markets more than it does in small and large market size levels. 
Table 4: OLS regressions of years until first entry on market size

\begin{tabular}{lcccc}
\hline Years until first entry & \multicolumn{2}{c}{ (1) } & \multicolumn{2}{c}{$(\mathbf{2})$} \\
& Coeff. & S.E. & Coeff. & S.E. \\
Freq Warm Days & & & & \\
(Freq Warm Days) & -10.221 & 4.121 & & \\
2nd Quartile Freq Warm Days & 12.307 & 5.093 & & \\
3rd Quartile Freq Warm Days & & & -0.283 & 0.221 \\
4th Quartile Freq Warm Days & & & -0.422 & 0.282 \\
POP & -18.077 & 6.88 & -18.31 & 6.827 \\
(POP) & 5.256 & 1.385 & 5.181 & 1.379 \\
Median Income & -1.224 & 0.898 & -1.014 & 0.897 \\
pop growth & -0.265 & 0.511 & -0.218 & 0.485 \\
\# of indoor theaters & -0.015 & 0.049 & -0.011 & 0.049 \\
tv rate & -0.382 & 0.348 & -0.424 & 0.347 \\
motorization & -0.991 & 0.565 & -0.929 & 0.588 \\
Urban Pop Share & 0.261 & 0.46 & 0.117 & 0.46 \\
Employment Share & -3.548 & 2.111 & -4.18 & 2.082 \\
College Share & -7.164 & 4.55 & -6.992 & 4.532 \\
Adult Share & 4.09 & 2.322 & 4.953 & 2.341 \\
Black Share & 0.063 & 0.62 & -0.385 & 0.656 \\
Pop Density & 0.368 & 0.215 & 0.364 & 0.214 \\
Farm Value & 8.274 & 15.799 & 6.672 & 15.881 \\
Sample & $\mathrm{N}\{$ max $=1,2$ & $\mathrm{N}\{$ max $\}=1,2$ \\
Observations & 1,272 & 1,272 \\
\hline
\end{tabular}

Notes: Coefficients of OLS regressions reported at the county level for all counties that either had one or two drive-in theaters in our sample. Column (1) uses both population and frequency of warm days. Column (2) uses quartiles of frequency of warm days to measure non-monotonicity between years until first entry and market size.

\subsection{Additional regression results}

The previous analysis used variation in market size to identify the incentive of firms to preempt entry. Another implication of the theory is that the number of firms that choose to enter the market in the long run is strictly increasing in market size. We use this second prediction to validate our proxy variable for market size. More specifically, if the number of warm days is positively correlated with market size (good proxy), the theory predicts a non-monotonic relationship with the probability of an early entry, and a monotonic relationship with the number of incumbents in the steady-state.

Table 5 examines the relationship between the total number of drive-in theaters observed in a county during our sample period and our market-size proxy. To do so, we run OLS 
regressions of the maximum number of drive-in theaters observed in a county during our sample period on the frequency of warm days and its square. As expected, the maximum number of entrants is positively correlated with market size. Note that, even though results in columns 1 and 3 look like showing non-monotonicity, their reflection points lie at 0.921 and 0.737 values of frequency of warm days. These values are above most of the data points in our sample, so we can conclude that non-monotonicity cannot be found in these regressions (see in Table 1 that the maximum value of frequency of warm days is 0.782$)$. Moreover, specifications in columns 2 and 4 use dummies per quartile of frequency of warm days and clearly show a positive relationship between the maximum number of drive-in theaters observed and the frequency of warm days.

Table 5: OLS regressions of the maximum number of entrants and market size

\begin{tabular}{|c|c|c|c|c|c|c|c|c|}
\hline \multirow[t]{2}{*}{$\operatorname{Max} \mathbf{N}$} & \multicolumn{2}{|c|}{ (1) } & \multicolumn{2}{|c|}{ (2) } & \multicolumn{2}{|c|}{ (3) } & \multicolumn{2}{|c|}{ (4) } \\
\hline & Coeff. & S.E. & Coeff. & S.E. & Coeff. & S.E. & Coeff. & S.E. \\
\hline Freq Warm Days & 7.132 & 2.376 & & & 8.533 & 1.956 & & \\
\hline (Freq Warm Days) $^{2}$ & -3.871 & 2.907 & & & -5.787 & 2.455 & & \\
\hline 2nd Quartile Freq Warm Days & & & 0.197 & 0.134 & & & 0.206 & 0.107 \\
\hline 3rd Quartile Freq Warm Days & & & 1.071 & 0.162 & & & 1.095 & 0.129 \\
\hline 4th Quartile Freq Warm Days & & & 1.228 & 0.205 & & & 1.287 & 0.166 \\
\hline POP & 9.652 & 1.093 & 9.937 & 1.09 & 7.725 & 0.968 & 8.185 & 0.966 \\
\hline$(\mathrm{POP})^{2}$ & -1.944 & 0.184 & -1.98 & 0.184 & -1.737 & 0.165 & -1.804 & 0.165 \\
\hline Median Income & 0.722 & 0.555 & 0.852 & 0.551 & 0.173 & 0.439 & 0.426 & 0.438 \\
\hline pop growth & 1.097 & 0.287 & 1.342 & 0.268 & 1.31 & 0.238 & 1.46 & 0.224 \\
\hline \# of indoor theaters & 0.146 & 0.012 & 0.142 & 0.012 & 0.162 & 0.011 & 0.157 & 0.011 \\
\hline tv rate & 0.47 & 0.221 & 0.353 & 0.217 & 0.336 & 0.174 & 0.226 & 0.172 \\
\hline motorization & -0.532 & 0.353 & -0.159 & 0.361 & -0.502 & 0.264 & -0.138 & 0.27 \\
\hline Urban Pop Share & 1.256 & 0.285 & 1.267 & 0.284 & 2.47 & 0.216 & 2.413 & 0.216 \\
\hline Employment Share & -4.321 & 0.976 & -4.029 & 0.966 & -4.764 & 0.867 & -4.246 & 0.857 \\
\hline College Share & 0.221 & 2.631 & -0.148 & 2.613 & 0.276 & 2.18 & 0.466 & 2.166 \\
\hline Adult Share & -1.53 & 1.43 & -1.097 & 1.425 & -2.12 & 1.112 & -2.187 & 1.112 \\
\hline Black Share & -0.312 & 0.401 & -0.215 & 0.428 & -0.591 & 0.313 & -0.536 & 0.338 \\
\hline Pop Density & -0.494 & 0.024 & -0.486 & 0.024 & -0.499 & 0.022 & -0.493 & 0.022 \\
\hline Farm Value & 28.457 & 5.495 & 31.375 & 5.508 & 29.674 & 4.908 & 33.207 & 4.917 \\
\hline Sample & \multicolumn{2}{|c|}{$\mathrm{N}\{\max \}>0$} & \multicolumn{2}{|c|}{$\mathrm{N}\{\max \}>0$} & \multicolumn{2}{|c|}{ All markets } & \multicolumn{2}{|c|}{ All markets } \\
\hline Observations & \multicolumn{2}{|c|}{2,193} & \multicolumn{2}{|c|}{2,061} & \multicolumn{2}{|c|}{2,911} & \multicolumn{2}{|c|}{2,911} \\
\hline
\end{tabular}

Notes: Coefficients of OLS regressions reported at the county level for all counties and those with at least one entrant in our sample. Columns (1) and (3) use both population and frequency of warm days. Columns (2) and (4) use quartiles of frequency of warm days to measure non-monotonicity between max number of entrants and market size.

While not shown here, we also undertake additional robustness checks. Related to the exercise in Table 5, we create a dummy that takes value 1 if entry was observed in a county between 1950 and 1955. As shown in Table 1, 69\% of counties experienced entry at least 
once after 1950 and therefore this is a more common event than entry prior to 1950 (19\%). We run probit regressions of this dummy variable on frequency of warm days, population, their corresponding squared variables and county demographics and find no evidence of nonmonotonicity.

Also not shown here, our robustness checks experiment with the early entry dependent variable and the temperature-based market definition variables. On the one hand, we check the sensitivity of our results to the definition of early entry by introducing a dummy "prior 1951 " as the dependent variable instead of the dummy "prior to 1950" used in Table 3. This exercise serves the purpose to mitigate the concern that our results are produced by some factors specific to 1949. Our findings are robust to this change in the dependent variable, and we still find a non-monotonicity in the relationship between the probability of entry and market size. On the other hand, we also use different definitions of market size to check that our results are not driven by our definition of a good weather day, namely, the percentage of days over 25 degrees Celsius in a county. To check the robustness of our market size measure, we alternatively constrain our original market size variable to the percentage of days between 25 and 35 degrees Celsius, between 20 and 30 degrees, and between 20 and 35. Our results of non-monotonicity are robust to changes in the definition of our market size variable.

\section{An empirical model of entry and technology diffusion}

In this section, we extend the simple model of entry with preemption gains presented in Section 3 to pursue structural estimation. By doing so, our objective is twofold. First, we use the model to quantify the importance of technological progress and diffusion that occurred over time in the industry. Second, we use the estimated model the quantify the effect of strategic entry preemption on market structure and welfare. In order to bring the model to the data, we enrich the two-period model by incorporating two stochastic elements that allow us to explain the observed diffusion patterns: (i) idiosyncratic profit shocks, and (ii) market-level unobserved heterogeneity. Our structural estimation also incorporates heterogeneity across markets by means of observed differences in market characteristics. 


\subsection{Payoff functions and market structure}

Consider a number of markets $i=1, \ldots, m$ during a number of periods $t=1, \ldots, T$. In period $t=1$, each market includes $N$ symmetric potential entrants. In period $t$, market $i$ has $N_{i t}$ potential entrants $j=1, \ldots N_{i t}$. Depending on its activity status $a_{j t}=\{0,1\}$, namely entering or staying out, firm $j$ earns the following variable profit function:

$$
\Pi_{i j, t}\left(a_{j t} \mid n, \epsilon_{i, t}\right)= \begin{cases}\pi_{i, t}(n)+\epsilon_{i j t, 1} & \text { If } a_{j t}=1, \\ 0+\epsilon_{i j t, 0} & \text { If } a_{j t}=0 .\end{cases}
$$

Where $\epsilon_{i j t, a}$ is private-value idiosyncratic profit shock, distributed independently across players according to a type-1 extreme-value distribution and associated with the value of entering or stay out of the market. The idiosyncratic profit shock is realized upon entry for new entrants and no entry for those staying out. Incumbent firms earn payoff $\pi_{i, t}(n)$ after entering.

We approximate the profit of entering using the following reduced-form form function:

$$
\begin{array}{r}
\pi_{i, t}(n)=M_{i} \frac{\ln \left(1+\exp \left(y_{i, t}\right)\right)}{(1+n)^{\theta}}, \\
y_{i, t}=x_{i} \beta_{x}+\beta_{t} \ln t+u_{i}, \\
u_{i} \sim^{i i d} N\left(0, \sigma_{u}^{2}\right),
\end{array}
$$

where $M_{i}$ is the fraction of warm days (proxy for market size). The numerator, $\ln (1+\exp (\cdot))$, determines the average profit per days open. The functional form ensures that variable profits are always positive, and nests the Cournot profit function if $\theta=2 .{ }^{3}$ Under this specification, differences in monopoly profits across markets are monotonically increasing in $y$. We use observed differences in demographics characteristics across markets in $x_{i}$, and account for unobserved market profitability using a time-invariant random-effect $u_{i} \cdot{ }^{4}$ Finally, $\beta_{t}$ measures the rate of technical progress affecting the variable profit. A positive value for $\beta_{t}$ is consistent

\footnotetext{
${ }^{3}$ We also estimate a restricted model where the profit function is derived from a Cournot model with a residual demand curve $P_{i, t}(Q)=a_{i, t}-b Q$ and a variable cost curve $C_{i t}(q)=c q$. The equilibrium price, quantity, and profit are given by $P_{i, t}^{*}\left(a_{i, t}, c, n_{i, t+1}\right)=\frac{a_{i t}+c n_{i, t+1}}{1+n_{i, t+1}}, q_{i, t}^{*}\left(a_{i, t}, b, c, n_{i, t+1}\right)=\frac{a_{i t}-c}{b\left(1+n_{i, t+1}\right)}$, and $\pi_{i, t}^{*}=$ $\frac{\left(a_{i t}-c\right)^{2}}{b\left(1+n_{i, t+1}\right)^{2}}+\sigma_{\epsilon} \epsilon_{i t, 1}$. Our results are qualitatively similar.

${ }^{4}$ Since the profit shock $u_{i, t}$ has full support, we use a ln transformation to decrease the rate at which the profit function increases $u$. Alternatively, when we use $\pi_{i, t}(n)=M_{i} \times \exp \left(x_{i} \beta_{x}+\beta_{t} \ln t+u_{i}\right) /(1+n)^{\theta}$, large realizations of $u_{i}$ imply a zero probability of staying out of the market for some values of the parameters, which creates numerical difficulties when maximizing the likelihood function.
} 
with improvements in the quality of the product over time (e.g. variety of movies available), or a reduction in the marginal cost of serving consumers.

The other component of profits is the fixed-cost of entering the market. Without loss of generality, we assume that this cost is paid once at the time of entry, and changes over time as the technology matures:

$$
F_{i, t}=z_{i} \gamma_{z}+\gamma_{t} \ln t
$$

Since we normalize the profit of non-entering to zero, $z_{i} \gamma_{z}$ measures the sunk cost of entering net of the value of staying out. In addition to an intercept, we include in $z_{i}$, proxies for the cost of acquiring land: population density and the value of farm products. We interpret the parameter $\gamma_{t}$ as the rate of technological progress associated to the initial investment.

The timing of the game proceeds as follows: (i) potential entrants observe the number of incumbent firms $n_{i, t}$ and decide to enter or not; (ii) the number of entrants is realized and firms earn the profit associated with $n_{i, t+1}$ incumbents; (iii) the game moves to period $t+1$ with $n_{i, t+1}$ as the new number of incumbents. Note that since profits are realized at the "end" of each period, $n_{i, t+1}$ is a random variable used to compute profits of incumbents and new entrants in period $t$. For instance, $n_{i, T+1}$ denotes the number of firms in the market in the last period of the game.

Since we assume that firms cannot exit the market, the number of incumbents evolves over time according to the following Markov process determined by firms' entry probability:

$$
P_{i, t}^{\sigma}\left(n_{i, t+1} \mid n_{i, t}\right)= \begin{cases}\mathrm{B}\left(N-n_{i, t}, n_{i, t+1}-n_{i, t}, \sigma_{i, t}\left(n_{i, t}\right)\right) & \text { if } n_{i, t}<N \\ 1 & \text { if } n_{i, t}=n_{i, t+1}=N\end{cases}
$$

where $\sigma_{i, t}\left(n_{i, t}\right)$ is the firm-level entry probability, and $B(\cdot)$ is the Binomial probability distribution. Similarly, from the point of view of potential entrants, the probability of facing competition from $n_{i, t+1}$ firms conditional on taking action $a_{i j, t} \in\{0,1\}$ is given by:

$$
\begin{aligned}
& P_{i, t}^{\sigma}\left(n_{i, t+1} \mid a_{i j, t}, n_{i, t}\right) \\
& = \begin{cases}\mathrm{B}\left(N-n_{i, t}-1, n_{i, t+1}-a_{i j, t}-n_{i, t}, \sigma_{i, t}\left(n_{i, t}\right)\right) & \text { if } n_{i, t}+a_{i j, t}<N \\
1 & \text { if } n_{i, t}+a_{i j, t}=n_{i, t+1}=N\end{cases}
\end{aligned}
$$


We refer to $\sigma=\left\{\sigma_{i, t}(n)\right\}_{n=0, \ldots, N, t=1, \ldots, T}$ as the strategy profile of potential entrants. The second term in both equations is equal to one because we assume a finite number of potential entrants. In practice, we choose $N$ so that this boundary condition is unlikely to be satisfied in equilibrium in the observed markets.

Given a strategy profile $\sigma$ for rivals, the expected profit of being active in the market is given by:

$$
\begin{aligned}
\bar{\pi}_{i, t}^{\sigma}\left(n_{i, t}\right) & =E_{n_{i, t+1}}\left[\pi_{i, t}\left(n_{i, t+1}\right) \mid n_{i, t}\right] \\
& =\sum_{n_{i, t+1} \geq n_{i, t}} P_{i, t}^{\sigma}\left(n_{i, t+1} \mid n_{i, t}\right) \pi_{i, t}\left(n_{i, t+1}\right)
\end{aligned}
$$

The net-present value of being an incumbent in market $i$ and period $t$ is defined recursively as:

$$
W_{i, t}^{\sigma}\left(n_{i, t}\right)= \begin{cases}\frac{\bar{\pi}_{i, t}^{\sigma}\left(n_{i, t}\right)}{1-\delta} & \text { If } t=T \\ \bar{\pi}_{i, t}^{\sigma}\left(n_{i, t}\right)+\delta E_{n_{i, t+1}}\left[W_{i, t+1}\left(n_{i, t+1}\right) \mid n_{i, t}\right] & \text { If } t<T\end{cases}
$$

where $\delta=0.9$ is the annual discount factor.

For potential entrants, the expected value of entering the market (net of $\epsilon_{i j t, 1}$ ) is given by:

$$
\begin{aligned}
v_{i, t}^{\sigma}\left(1 \mid n_{i, t}\right) & =E_{n_{i, t+1}}\left[\pi_{i, t}\left(n_{i, t+1}\right)-F_{i, t}+\delta W_{i, t+1}^{\sigma}\left(n_{i, t+1}\right) \mid n_{i, t}, a_{i j, t}=1\right] \\
& =\sum_{n_{i, t+1} \geq n_{i, t}+1} P_{i, t}^{\sigma}\left(n_{i, t+1} \mid a_{i j, t}=1, n_{i, t}\right)\left[\pi_{i, t}\left(n_{i, t+1}\right)-F_{i, t}+\delta W_{i, t+1}^{\sigma}\left(n_{i, t+1}\right)\right] .
\end{aligned}
$$

Similarly, the value of not entering in period $t$ is determined by the option value of entering in $t+1$ :

$$
v_{i, t}^{\sigma}\left(0 \mid n_{i, t}\right)=\delta E_{n_{i, t+1}}\left[V_{i, t+1}^{\sigma}\left(n_{i, t+1}\right) \mid a_{i j, t}=0, n_{i, t}\right]
$$

where

$$
V_{i, t}^{\sigma}\left(n_{i, t}\right)=E_{\epsilon}\left[\max \left\{v_{i, t}^{\sigma}\left(1 \mid n_{i, t}\right)+\epsilon_{i j t, 1}, v_{i, t}^{\sigma}\left(0 \mid n_{i, t}\right)+\epsilon_{i j t, 0}\right\}\right]=\ln \left(\sum_{a} \exp \left(v_{i, t}^{\sigma}\left(a \mid n_{i, t}\right)\right)\right)+\gamma
$$

is the expected value function of potential entrants with $\gamma$ being the Euler constant. As in Rust (1987), the second equality follows from the type-1 extreme value distribution assumption on payoff shocks $\epsilon_{i j t, 0}$ and $\epsilon_{i j t, 1}$. 
Given a belief $\sigma$ about rivals' entry probabilities, the optimal entry strategy of a potential entrant can be summarized by the following entry probability:

$$
\operatorname{Pr}\left(a_{i j, t}=1 \mid \sigma, n_{i, t}, y_{i, t}, F_{i, t}\right) \equiv \Lambda_{i, t}\left(\sigma \mid n_{i, t}\right)=\frac{\exp \left(v_{i, t}^{\sigma}\left(1 \mid n_{i, t}\right)\right)}{\exp \left(v_{i, t}^{\sigma}\left(0 \mid n_{i, t}\right)\right)+\exp \left(v_{i, t}^{\sigma}\left(1 \mid n_{i, t}\right)\right)}
$$

As in Aguirregabiria and Mira (2007), we refer to this mapping as the best-response probability function.

\subsection{Equilibrium solution}

We focus on symmetric Markov-Perfect Bayesian Nash equilibrium (MPE). We follow Aguirregabiria and Mira (2007) in defining our equilibrium in terms of entry probabilities. A strategy profile $\sigma_{i}^{*}=\left\{\left\{\sigma_{i, t}^{*}(n)\right\}_{n=1, \ldots, N}, \sigma_{i, 1}^{*}(0)\right\}_{t=1, \ldots, T}$ is an MPE if the vector entry probabilities are consistent with firms' best-response strategies in every state $n$ and time periods. Definition 1 defines formally the equilibrium of this game.

Definition 1. Strategy profile $\sigma^{*}$ is a Markov-perfect Bayesian Nash equilibrium for market $i$ if $\sigma_{i, t}^{*}\left(n_{i, t}\right)$ is a fixed-point to the following best-response entry probability mapping:

$$
\sigma_{i, t}^{*}\left(n_{i, t}\right)=\Lambda_{i, t}\left(\sigma^{*} \mid n_{i, t}\right)=\frac{\exp \left(v_{i, t}^{\sigma^{*}}\left(1 \mid n_{i, t}\right)\right)}{\exp \left(v_{i, t}^{\sigma^{*}}\left(0 \mid n_{i, t}\right)\right)+\exp \left(v_{i, t}^{\sigma^{*}}\left(1 \mid n_{i, t}\right)\right)}, \quad \text { for all } n_{i t} \text { and } t
$$

We obtain the solution to this MPE using backward induction. In period $t=T$ and state $n_{i T}$, the model reduces to a static entry game with $N-n_{i t}$ symmetric potential entrants, and incomplete information. Since $\epsilon_{i j t}$ has full support, there exists a unique symmetric Bayesian Nash equilibrium for this stage game. This equilibrium can be found easily by iterating on the best-response probability mapping. In period $T-1$, firms play a similar entry game, taking as given the equilibrium value of being an incumbent in period $T: W_{i, T}^{\sigma^{*}}\left(n_{i, t}\right)$. Using the same argument, there exists a unique Bayesian Nash equilibrium in period $T-1$, as well as all periods $t<T-1$. Crucially, this implies that there exists a unique symmetric MPE.

The existence and uniqueness of an MPE in this context is consistent with arguments in Doraszelski and Satterthwaite (2010) that industry dynamic models with single-direction Markov transitions exhibit unique Markov-perfect bayesian equilibrium. An equilibrium exists because of our assumption that the private-information profit shocks have full support, 
guarantying the existence of an interior solution to the best-response probability fixed-point (see Pesendorfer and Schmidt-Dengler, 2008). Uniqueness is guaranteed because of our assumption that incumbents cannot exit the market. As we discussed above, this equilibrium selection assumption is reasonable in a non-stationary market like the one we are studying. We exploit this property in the next section when constructing our estimator.

\subsection{Estimation}

\subsubsection{Sample restriction}

In the estimation of the structural model, we select a subset of counties from the full sample described in Section 2.2. Since theaters in the same county are assumed to be symmetric in our structural model, we drop large counties where markets are segmented and drive-in theaters in different segments do not directly compete against each other. ${ }^{5}$

We aggregate our data to 5 multi-year periods when estimating the structural model. Based on patterns shown in Table 2 and Figure 2, the 5 sub-periods are 1945-1947, 1948-1949, 1950-1951, 1952-1953, and 1954-1957. Besides, we assume the market structure is stable after 1957 (i.e., $T=6$ corresponds to years after 1957). Although we do not have data in period $T=6$, we include an extra period since the growth rate in the number of drive-in movie theaters per market was still positive in the last period of our data-set.

There are two considerations for the choice of time aggregation. First, entry is relatively rare, and on average the first theater enters after 5 years (see Table 1). On an annual basis, $70 \%$ of observations exhibit no entry. Rationalizing these patterns with the model would inflate the importance of the idiosyncratic profit shocks. On the other hand, using too few periods would limit our ability to measure an S-shape diffusion pattern from the number of theaters per market. The shape of the diffusion pattern is important to identify the relative importance of entry preemption incentive and technological progress. We balance these two issues by defining a period as a two- or three-year interval.

Second, as we discussed in the data section above, our data on the number of movie theaters is likely measured with error; either due to the data extraction process itself, imperfect recording on entry dates, or theater exit. Using a finer time aggregation results in a more

\footnotetext{
${ }^{5}$ Counties that fall into either one of the following three categories are dropped: (1) having a population of more than 1 million people; (2) a population density above 1000 people per squared miles; or (3) having more than 4 active incumbent drive-in theaters at any point during our sample.
} 
volatile measure of entry, and can lead to "false" exit. This is particularly relevant later in the sample since the 1954 recession caused temporary exits and/or changes of theater names. Since our model cannot rationalize exit, aggregating across years leads to a more stable measure of the number of active theaters.

\subsubsection{Likelihood function and identification}

The parameter vector to be estimated is $\boldsymbol{\Theta}=\left(\beta, \gamma, \theta, \sigma_{u}\right)$, and let $X_{i}=\left\{x_{i}, z_{i}\right\}$ denote the vector of observed demographic characteristics of market $i$. We use a Nested-fixed point algorithm to estimate $\boldsymbol{\Theta}$. Given a guess of the parameters $\boldsymbol{\Theta}$ and integration grid points $u_{i} \in\left\{u_{\min }, \ldots, u_{\max }\right\}$ (i.e. 'types'), we can calculate the likelihood function as follows.

First, we solve the model for each market/type combination as described in previous Section 4.2. The likelihood contribution of observing a sequence of entry summarized by the number of incumbents in each period $\left(n_{i 1}, n_{i 2}, \ldots, n_{i, t}\right)$ :

$$
\operatorname{Pr}\left(n_{i 2}, \ldots, n_{i, T-1} ; u_{i}, n_{i 1}=0, X_{i}, \boldsymbol{\Theta}\right)=\prod_{t=1}^{T-1} \operatorname{Pr}\left(n_{i, t+1} \mid n_{i, t}, u_{i}, X_{i}, \boldsymbol{\Theta}\right)
$$

where $\operatorname{Pr}\left(n_{i, t+1} \mid n_{i, t},, u_{i}, X_{i}, \boldsymbol{\Theta}\right)$ is the probability of observing $n_{i, t+1}$ incumbents at the end of period $t$ conditional on having $n_{i, t}$ at the beginning. The transition probability is given by equation (6), evaluated at the Nash equilibrium entry probability for a market of type $u_{i}$ with observed characteristics $X_{i}$. As mentioned in the previous subsection, we only have data before period $T$, so the probability is calculated from $t=1$ to $T-1$.

Integrating over the distribution of types, the likelihood contribution of observation $i$ is

$$
\begin{aligned}
l_{i}\left(n_{i 2}, \ldots, n_{i, T-1} ; X_{i}, \boldsymbol{\Theta}\right) & =\int_{u} \phi\left(\frac{u}{\sigma_{u}}\right) \operatorname{Pr}\left(n_{i 2}, \ldots, n_{i, T-1} ; u, n_{i 1}=0, X_{i}, \boldsymbol{\Theta}\right) d u \\
& \approx \sum_{k} \frac{\omega_{k}}{\sqrt{\pi}} \operatorname{Pr}\left(n_{i 2}, \ldots, n_{i, T-1} ; u_{k}, X_{i}, \boldsymbol{\Theta}\right)
\end{aligned}
$$

where the approximation uses Gauss-Hermite quadrature method.

Second, we use simulated maximum likelihood method to estimate the model where parameter estimates maximize the likelihood function. We use several ways to make sure that the estimates are not local maxima. ${ }^{6}$

\footnotetext{
${ }^{6}$ We use different starting values for the parameter guess and choose the estimates that give the greatest likelihood. We use Julia to solve the dynamic entry game and Julia solver Optim to maximize the likelihood.
} 
The preference parameters are identified from variations across markets in the shape of the diffusion pattern. The coefficients associated with the demographic variables $x_{i}$ and $z_{i}$ are identified by comparing the speed of diffusion across markets with observably different characteristics. We impose restrictions on this relationship by assuming that population density and farm value affect the fixed-cost, while other socio-demographic characteristics of the county affect the variable profit.

Conditional on $\left(x_{i}, z_{i}\right)$, the speed of diffusion is determined by the competition parameter $(\theta)$ and the rate of technological progress $\left(\gamma_{t}, \beta_{t}\right)$. Heuristically, the model imposes three types of restrictions on the data. First, absent of any preemption incentives (e.g. large $M_{i}$ markets), the observed growth in the number of theaters identifies the technology parameters. Differences in this rate across markets with observed differences in fixed-cost and/or variable profits identify the relative importance of $\gamma_{t}$ and $\beta_{t}$. Second, the other restriction imposed by the model is related to the preemption incentive. As we discussed in Section 3, the concave reduced-form relationship between market-size (number of warm days) and diffusion speed identifies the relative importance of the cost and benefit of preemption; determined in the model by $\theta$ and $\left(\beta_{t}, \gamma_{t}\right)$. Third, the model also imposes restrictions on the reducedform relationship between the probability of observing a new entrant, and the number of incumbents. Everything else being equal, an increase in the number of incumbents leads to a reduction in the probability of entry.

Finally, the importance of unobserved heterogeneity across markets is related to the degree of serial correlation in the number of entrants within each market (conditional on observable characteristics). In particular, unobserved heterogeneity implies a positive correlation between entry $\left(\Delta n_{i t}\right)$ and the number of incumbents $n_{i t}$. Markets with high unobserved profits $\left(u_{i}\right)$ exhibit a higher probability of entry, and a large number of incumbents in period $T-1$ (and vice versa for low $u_{i}$ markets). By contrast, the effect of competition $(\theta>1)$ implies a negative relationship between the number of incumbents and the probability of entering. If $\sigma_{u}>0$, these two opposite forces can lead to a positive reduced-form relationship between the number of entrants and incumbents, despite $\theta>1$. In our data, conditional on observed characteristics, we find that an additional incumbent is associated with an increase of .5 in the number of new entrants (results available upon request). This suggests that unobserved heterogeneity is quite important. Failing to account for this would therefore lead to biased 
estimates of the competition parameter and/or the rate of technological progress, given that both sets of parameters determine the predicted persistence in the rate of entry over time.

\subsection{Parameter estimates}

The estimation results are reported in Table 6. Column (1) reports the baseline specification outlined in the previous subsection. Columns (2)-(5) report the estimates from 4 restricted models. Model (2) imposes the assumption of Cournot competition where the competition parameter $\theta$ in the profit function is restricted to 2. Models (3) and (4) eliminate the time trend in sunk entry cost and variable profit, respectively. Model (5) eliminates the marketlevel unobservable heterogeneity in variable profit (i.e., $\sigma_{u}=0$ ). For the restricted models, a $\chi^{2}$ statistic for the likelihood ratio test against the baseline model (1) is also reported. The $\chi^{2}$ statistic is calculated as $2\left(\ell-\ell_{0}\right)$ where $\ell_{0}$ and $\ell$ are respectively the log-likelihood of the baseline unrestricted model and that of the restricted model.

The parameter estimates in the variable profit are consistent across different specifications. First, as the number of incumbents increases, variable profit declines at a lower rate than that in a Cournot model (except for Model (2) where Cournot competition is imposed). Second, average daily variable profit increases with population size, median income, share of urban population, and share of collage graduates. All else equal, variable profit decreases with share of black population, share of employment, and share of adult population. Lastly, there is a rising time trend in variable profit $\left(\beta_{t}>0\right)$.

The parameter estimates in the entry cost are also consistent across different specifications. Our results show across all specifications that entry cost increases with population density and farm land value. It follows that both population density and farm land value increases the cost of land acquisition. Moreover, there is a declining time trend in entry cost $\left(\gamma_{t}<0\right)$ as anticipated. 
Table 6: Simulated maximum likelihood estimates of the structural model

\begin{tabular}{|c|c|c|c|c|c|}
\hline & $\begin{array}{c}(1) \\
\text { Baseline }\end{array}$ & $\begin{array}{c}(2) \\
\text { Cournot } \\
\end{array}$ & $\begin{array}{c}(3) \\
\gamma_{1}=0\end{array}$ & $\begin{array}{c}(4) \\
a_{1}=0\end{array}$ & $\begin{array}{c}(5) \\
\sigma_{u}=0 \\
\end{array}$ \\
\hline$\sigma_{u}$ & $\begin{array}{c}4.607 \\
(0.198)\end{array}$ & $\begin{array}{l}7.186 \\
(0.113)\end{array}$ & $\begin{array}{c}3.433 \\
(0.103)\end{array}$ & $\begin{array}{c}1.97 \\
(0.063)\end{array}$ & \\
\hline$\theta$ & $\begin{array}{c}1.58 \\
(0.043)\end{array}$ & 2.0 & $\begin{array}{c}1.224 \\
(0.029)\end{array}$ & $\begin{array}{c}1.12 \\
(0.026)\end{array}$ & $\begin{array}{c}1.513 \\
(0.055)\end{array}$ \\
\hline Variable profit $(\beta)$ : & & & & & \\
\hline Population (10k) & $\begin{array}{c}2.83 \\
(0.136)\end{array}$ & $\begin{array}{c}4.163 \\
(0.093)\end{array}$ & $\begin{array}{l}1.925 \\
(0.075)\end{array}$ & $\begin{array}{c}1.537 \\
(0.069)\end{array}$ & $\begin{array}{c}2.096 \\
(0.128)\end{array}$ \\
\hline Income & $\begin{array}{l}2.413 \\
(0.615)\end{array}$ & $\begin{array}{c}2.32 \\
(1.122)\end{array}$ & $\begin{array}{c}2.765 \\
(0.596)\end{array}$ & $\begin{array}{l}2.086 \\
(0.404)\end{array}$ & $\begin{array}{l}1.691 \\
(0.426)\end{array}$ \\
\hline Urban share & $\begin{array}{l}14.202 \\
(0.74)\end{array}$ & $\begin{array}{l}22.546 \\
(0.59)\end{array}$ & $\begin{array}{c}9.683 \\
(0.467)\end{array}$ & $\begin{array}{c}6.35 \\
(0.347)\end{array}$ & $\begin{array}{c}8.462 \\
(0.581)\end{array}$ \\
\hline Employment share & $\begin{array}{l}-1.992 \\
(0.256)\end{array}$ & $\begin{array}{l}-3.253 \\
(0.841)\end{array}$ & $\begin{array}{l}-3.846 \\
(1.511)\end{array}$ & $\begin{array}{l}-0.683 \\
(0.445)\end{array}$ & $\begin{array}{l}-0.839 \\
(0.725)\end{array}$ \\
\hline College share & $\begin{array}{l}19.394 \\
(3.668)\end{array}$ & $\begin{array}{l}33.751 \\
(6.477)\end{array}$ & $\begin{array}{l}12.612 \\
(2.812)\end{array}$ & $\begin{array}{l}9.983 \\
(2.116)\end{array}$ & $\begin{array}{l}14.391 \\
(2.444)\end{array}$ \\
\hline Adult share & $\begin{array}{l}-9.463 \\
(2.602)\end{array}$ & $\begin{array}{c}-16.28 \\
(4.3)\end{array}$ & $\begin{array}{l}-5.698 \\
(2.004)\end{array}$ & $\begin{array}{l}-4.521 \\
(1.329)\end{array}$ & $\begin{array}{l}-7.775 \\
(1.788)\end{array}$ \\
\hline Black share & $\begin{array}{l}-2.712 \\
(0.755)\end{array}$ & $\begin{array}{l}-3.107 \\
(1.148)\end{array}$ & $\begin{array}{l}-2.332 \\
(0.548)\end{array}$ & $\begin{array}{l}-2.309 \\
(0.413)\end{array}$ & $\begin{array}{l}-2.531 \\
(0.475)\end{array}$ \\
\hline Intercept & $\begin{array}{c}-14.911 \\
(1.432)\end{array}$ & $\begin{array}{l}-23.809 \\
(2.524)\end{array}$ & $\begin{array}{l}-15.398 \\
(1.926)\end{array}$ & $\begin{array}{l}1.601 \\
(0.902)\end{array}$ & $\begin{array}{l}-5.916 \\
(1.151)\end{array}$ \\
\hline Log-trend $\left(\beta_{t}\right)$ & $\begin{array}{l}11.642 \\
(0.565)\end{array}$ & $\begin{array}{l}18.63 \\
(0.331)\end{array}$ & $\begin{array}{l}12.578 \\
(0.45)\end{array}$ & & $\begin{array}{l}4.911 \\
(0.327)\end{array}$ \\
\hline Fixed entry cost $(\gamma)$ : & & & & & \\
\hline Population density & $\begin{array}{c}9.933 \\
(0.3)\end{array}$ & $\begin{array}{c}4.393 \\
(0.087)\end{array}$ & $\begin{array}{l}11.585 \\
(0.264)\end{array}$ & $\begin{array}{l}7.256 \\
(0.213)\end{array}$ & $\begin{array}{c}5.064 \\
(0.227)\end{array}$ \\
\hline Farm value & $\begin{array}{l}88.123 \\
(9.193)\end{array}$ & $\begin{array}{l}66.921 \\
(7.84)\end{array}$ & $\begin{array}{l}96.199 \\
(6.975)\end{array}$ & $\begin{array}{l}65.544 \\
(9.158)\end{array}$ & $\begin{array}{l}61.218 \\
(5.907)\end{array}$ \\
\hline Intercept & $\begin{array}{c}5.632 \\
(0.185)\end{array}$ & $\begin{array}{c}5.454 \\
(0.145)\end{array}$ & $\begin{array}{c}5.558 \\
(0.193)\end{array}$ & $\begin{array}{c}6.479 \\
(0.224)\end{array}$ & $\begin{array}{c}3.935 \\
(0.116)\end{array}$ \\
\hline Log-trend $\left(\gamma_{t}\right)$ & $\begin{array}{l}-1.223 \\
(0.016)\end{array}$ & $\begin{array}{l}-1.355 \\
(0.009)\end{array}$ & & $\begin{array}{l}-2.387 \\
(0.047)\end{array}$ & $\begin{array}{c}-1.2 \\
(0.016)\end{array}$ \\
\hline $\begin{array}{l}\text { Log-likelihood } \\
\chi^{2}(d f)\end{array}$ & -7144.87 & $\begin{array}{l}-7156.111 \\
22.481(1)\end{array}$ & $\begin{array}{l}-7215.532 \\
141.325(1)\end{array}$ & $\begin{array}{l}-7248.104 \\
206.467(1)\end{array}$ & $\begin{array}{l}-7249.847 \\
209.955(1)\end{array}$ \\
\hline
\end{tabular}

Notes: $N=2571$. Standard errors clustered at the state level are reported in parentheses. The last row reports the $\chi^{2}$ statistic for likelihood ratio tests of restricted models (2)-(5) against the full model (1).

Specifications (3) and (4) restrict technological progress to operate only through variable profit or fixed-cost. Both restrictions are clearly rejected from the data. Based on the magnitude of the likelihood ratio tests and the parameter estimates, growth in variable profits due to quality or marginal cost is the most important factor to explain the data. Also, accounting for both trends has an important impact on our estimate of $\theta$ (i.e. effect of competition on profits). This is because the competitiveness of the market and technology jointly determine 
the predicted speed of diffusion of drive-in theaters. Failing to account for the two sources of technological progress leads to a biased estimate of the competition parameter.

Finally, controlling for unobserved market heterogeneity is crucial to fit the data, and to consistently estimate the magnitude of the trade-off between technological progress and entry preemption. Specification (5) shows that accounting for unobserved heterogeneity has the biggest impact on the fit of the model. Setting $\sigma_{u}=0$ also biases towards zero our estimate of technological improvement, and reduces the competition parameter from 1.58 to 1.51 .

\section{Measuring the value of commitment}

To quantify the magnitude of the preemption incentive, we consider a counter-factual environment in which firms could commit to an entry probability profile. In the first period, each potential entrant specifies and commits to a sequence of strategies for the following periods. Potential entrants cannot condition their strategy on the number of incumbents because it is not observed when they specify their strategy. This eliminates the possibility of preemption, since firms cannot affect future market structure by deciding to enter early. Instead, each player forms a belief of its rivals' sequence strategy such that its strategy is a best response to the rivals' strategy. The choice-specific value functions associated with entering and not entering market $i$ are respectively defined as

$\bar{v}_{i, t}^{\sigma}\left(a_{i, t}=1\right)=\sum_{n_{i, t}} Q_{i, t}^{\sigma}\left(n_{i, t}\right) \sum_{n_{i, t+1} \geq n_{i, t}+1} P_{i, t}^{\sigma}\left(n_{i, t+1} \mid a_{i, t}=1, n_{i, t}\right)\left[\pi_{i, t}\left(n_{i, t+1}\right)-F_{i, t}+\delta W_{i, t+1}\left(n_{i, t+1}\right)\right]$,

$\bar{v}_{i, t}\left(a_{i, t}=0\right)=\sum_{n_{i, t}} Q_{i, t}^{\sigma}\left(n_{i, t}\right) \sum_{n_{i, t+1} \geq n_{i, t}} P_{i, t}^{\sigma}\left(n_{i, t+1} \mid a_{i, t}=0, n_{i, t}\right) \delta W_{i, t+1}\left(n_{i, t+1}\right)$,

where $Q_{i, t}^{\sigma}\left(n_{i, t}\right)$ measures the probability of facing $n_{i, t}$ incumbents perceived by a potential entrant in period $t$, and $P_{i, t}^{\sigma}\left(n_{i, t+1} \mid a_{i, t}, n_{i, t}\right)$ is the conditional transition probability for the number of incumbents across periods. This latter function is given by the same binomial probability described in equation (7), in which the Markovian entry probability is replaced by the strategy with commitment. Similarly, the value of being an incumbent in period $t$ is 
$W_{i, t}\left(n_{i, t}\right)$, which is defined recursively by equation (9). ${ }^{7}$

Using equations (12) and (13), we can define the best-response entry probability mapping with commitment as follows:

$$
\Lambda_{i, t}^{c}(\sigma)=\frac{\exp \left(\tilde{v}_{i, t}^{\sigma}(1)\right)}{\exp \left(\bar{v}_{i, t}^{\sigma}(0)\right)+\exp \left(\bar{v}_{i, t}^{\sigma}(1)\right)}
$$

A Bayesian-Nash equilibrium of the game with commitment is therefore defined as a vector of beliefs $\sigma_{i}^{c}=\left\{\sigma_{i, t}^{c}\right\}_{t=1, \ldots, T}$ that is consistent with firms' optimal entry probabilities: ${ }^{8}$

$$
\sigma_{i, t}^{c}=\Lambda_{i, t}^{c}\left(\sigma^{c}\right)=\frac{\exp \left(\tilde{v}_{i, t}^{\sigma^{c}}(1)\right)}{\exp \left(\bar{v}_{i, t}^{\sigma^{c}}(0)\right)+\exp \left(\bar{v}_{i, t}^{\sigma^{c}}(1)\right)}, \quad \forall t .
$$

To quantify the effect of preemption using the observed markets, we first assign a profitability type $\bar{u}_{i}$ to each market using the posterior distribution of the random coefficients:

$$
\begin{aligned}
\bar{u}_{i}=\mathrm{E}\left(u_{i} \mid \boldsymbol{n}_{i}\right) & =\int u f\left(u \mid \boldsymbol{n}_{i}\right) d u \\
& =\int \frac{u f\left(\boldsymbol{n}_{i} \mid u\right)}{\int f\left(\boldsymbol{n}_{i} \mid u\right) f(u) d u} f(u) d u \\
& =\int \frac{u f\left(\boldsymbol{n}_{i} \mid u\right)}{\mathcal{L}_{i}(\boldsymbol{\Theta})} f(u) d u
\end{aligned}
$$

where $f(u)$ is the estimated prior of the probability density function of $u_{i} \sim N\left(0, \sigma_{u}^{2}\right), \mathcal{L}_{i}(\mathbf{\Theta})$ is the likelihood contribution from market $i$, and $f\left(\boldsymbol{n}_{i} \mid u\right)$ is the likelihood of observing entry sequence $\boldsymbol{n}_{i}$ in market $i$ conditional on the unobservable variable profit intercept $u$.

Then, given the posterior expected market-specific variable profit (16), variable profit and entry cost covariates $\left(x_{i}, z_{i}\right)$, and the estimated structural parameters $\hat{\boldsymbol{\Theta}}=\left(\hat{\theta}, \hat{\beta}, \hat{\gamma}, \hat{\sigma}_{u}\right)$ reported in Column (1) of Table 6, we can solve the dynamic entry game for each market under the two equilibrium concepts. This gives us the equilibrium entry probability in each period and the associated value functions.

To illustrate the relationship between preemption, market structure and welfare, we group markets in terms of profitability as measured by the profit of a monopolist in the steady state. We use monopoly profit instead of market size to illustrate the preemption motive because in

\footnotetext{
${ }^{7}$ The distribution of incumbents perceived by $Q_{i, t}^{\sigma}\left(n_{i, t}\right)$ is calculated by integrating over all possible sequences entry from period 1 to $t$. We show in Appendix B that $Q_{i, t}^{\sigma}\left(n_{i, t}\right)$ can be calculated recursively using the Law of Total Probability.

${ }^{8}$ The algorithm used to solve for $\sigma^{c}$ is described in the Appendix. Appendix B.3 illustrates the effect of commitment on the equilibrium market-structure using a numerical example.
} 
the data markets differ both in terms of $M$ and in terms of demographic characteristics (and $\left.\bar{u}_{i}\right)$. The profit of a monopolist summarizes this heterogeneity in a single index. Everything else being equal, markets with intermediate values of monopoly profits generate the largest benefit from preemption. In practice, markets also differ in their fixed-cost, and so there is not a one-to-one mapping between preemption incentives and profitability.

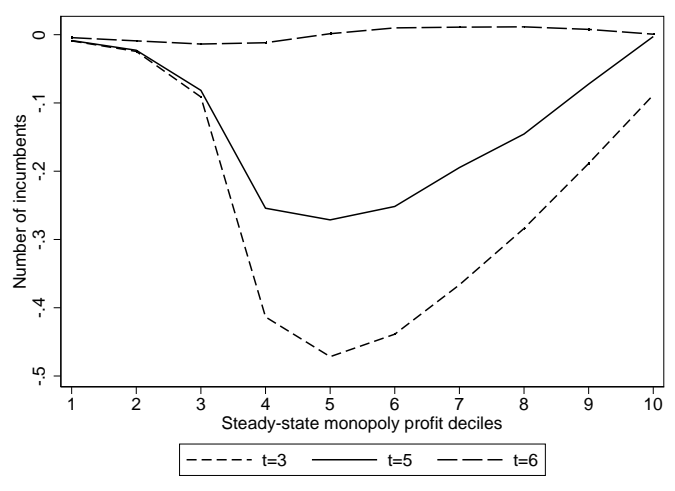

(a) Number of Incumbent

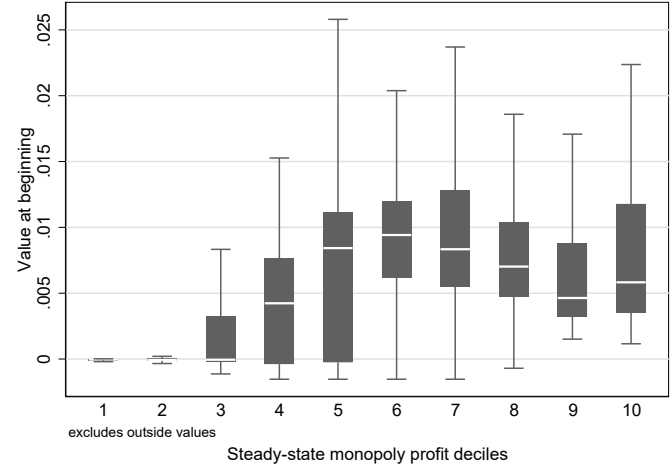

(b) $V_{i 1}$

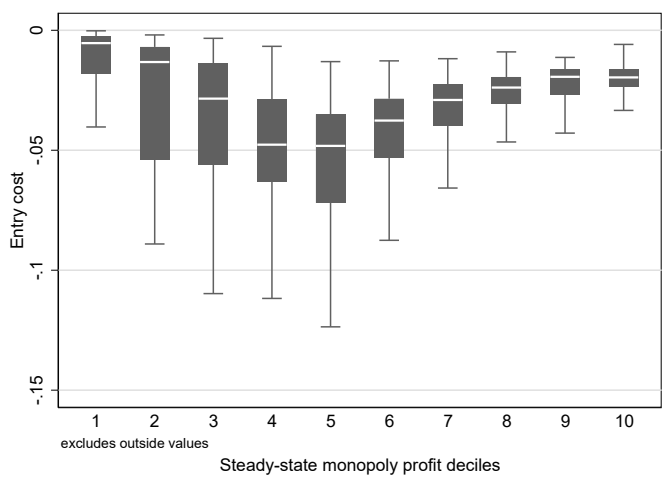

(c) Entry Cost

Figure 6: Differences in market structure and profitability with and without commitment

Notes: The figures plot the proportional change in their respective variables on the y-axis $Y$ under commitment relative to the MPE benchmark: $\left(Y_{i}^{\mathrm{Commit}}-Y_{i}^{\mathrm{MPE}}\right) / Y_{i}^{\mathrm{MPE}}$ for the expected number of (end of period $t$ ) incumbents $\mathrm{E}\left(n_{i, t+1}\right)$ in Figure $6(\mathrm{a})$, ex ante value of a potential entrant in market $i, V_{i 1}$ in Figure 6(b), and expected discounted sum of entry cost incurred $\mathrm{EC}_{i, t}=\sum_{t=1}^{T} \delta^{t} \mathrm{E}_{n_{i, t+1}}\left[\left(n_{i, t+1}-n_{i, t}\right) F_{i, t}\right]$ in Figure 6(c). The horizontal axis consists of the ten deciles of markets ranked by monopoly profitability in the steady-state: $\pi_{i, 6}(n=1)$. Figure $6(\mathrm{a})$ plots the median value within each bin. Figures $6(\mathrm{~b})$ and $6(\mathrm{c})$ plot the distribution of each variable within each profitability group, after winsorizing the top and bottom percentiles.

Figure 6(a) illustrates the effect of preemption on market structure. We do so by calculating the percentage change in the number of incumbents between the commitment equilibrium and MPE at each stage of the game. A negative value indicates a strong effect of entry preemption. The x-asis corresponds to each decile of the distribution of monopoly profits, and 
each curve represents the median value of the outcome variable within each decile.

The first thing to note is that the commitment and Markov equilibria generate roughly same number of firms in the final stage (i.e. the median of $E\left(n_{i, T}^{\text {Commit }}\right)-E\left(n_{i, T}^{\mathrm{MPE}}\right)$ at $T=6$ is close to zero for all deciles). Instead, preemption affects the timing of entry, and this effect is the largest in the early stages of the game. For markets in the middle of the profitability distribution, the model predicts that the number of incumbents is $50 \%$ smaller with commitment in $t=3$, compared to only $25 \%$ in $t=5$. Moreover, at each stage, preemption leads to a non-monotonic relationship between the number of incumbents and profitability. In $t=3$, expected differences in market structure are nearly zero for markets in the bottom and top deciles, but rise to nearly $50 \%$ near the median of the profitability distribution.

To evaluate the effect of these market structure differences on profitability, we calculate the ex ante value of a potential entrant in market $i, V_{i 1}$, and the expected discounted sum of entry costs incurred in each market, $\mathrm{EC}_{i, t}=\sum_{t=1}^{T} \delta^{t} \mathrm{E}_{n_{i, t+1}}\left[\left(n_{i, t+1}-n_{i, t}\right) F_{i, t}\right]$. Differences in $V_{i 1}$ measure the change in firm value between the commitment equilibrium and the MPE. A positive value implies that firms are better-off with commitment. Similarly, a negative value for the difference in entry costs implies that markets exhibit larger fixed costs under MPE.

In the Markov-perfect equilibrium, firms enter early to deter future entry, which leads to incurring higher fixed costs. The effect on variable profits is more ambiguous. On the one hand, firms that successfully delay entry of rivals earn lower profits upon entry (due to $\beta_{t}>0$ ), but earn higher profits afterwards due to deterrence. On the other hand, firms that delay their entry because of preemption earn positive profits for fewer periods, and face more competition upon entry. The net effect captures the expected value of entry preemption on firm value.

We illustrate these two variables using a series of box plots. Before we plot the graphs, we winsorize the variables at the top and bottom percentiles. As before, we divide counties into groups based on their profitability. Figures $6(\mathrm{~b})$ and $6(\mathrm{c})$ present the results. Overall, we find that firms are worse off under MPE ex-ante, suggesting that the ability to commit ex-ante increases firm values. Consistent with the discussion above, the net effect on value is small, since the ability to preempt entry generates winners and losers ex-post. The median increase in value is roughly $1 \%$ for markets in the 5 th and 6 th deciles. 
From a welfare point of view, the main effect of preemption appears to be the generation of wasteful investments, and as a result we find large effects of commitment on the discounted value of the entry cost. For medium-level profitability markets, the median change in the discounted sum of fixed-cost is roughly $5 \%$. Since preemption incentives are weak for low and high profitability markets, the distributions of differences go to zero for the top and bottom deciles.

\section{Conclusion}

In this paper, we empirically examine the prevalence of entry deterrence strategies and their impact on the dynamics of new industries using the inception and evolution of the U.S. drivein theater market between 1945 and 1957. Because the strategic entry deterrence effect of entering early is only relevant in markets of intermediate size, we argue that a non-monotonic relationship exists between market size and the probability of observing early entry. We find robust empirical support for this prediction using a comprehensive cross-section of county markets in the U.S. Furthermore, our structural estimation of the parameters of a dynamic entry game allows us to quantify the strength of the preemption incentive. Our counterfactual analyses show strategic motives can increase the number of early entrants by as much as 50 percent higher in middle-size markets but they do not have an effect on the overall number of entrants. On the one hand, this means that strategic preemption motives increase the overall entry costs incurred in a market. On the other hand, the presence of strategic motives does not seem to have a noticeable impact on the overall profits of firms.

Our finding is important because it sheds light on the effect of strategic incentives on the industry structure of new technologies and markets. On the one hand, early adoption may appear to be beneficial to consumers and late adopters due to the diffusion of knowledge and learning economies. On the other hand, if early adoption is driven by strategic entry deterring motives, when successful it may lead to long-term monopolies and market power concentration. In that case, consumers may be definitely worse off because of higher prices and lower quantity. Our analysis emphasizes this trade-off and shows no overall effect on the total number of firms operating in a market in the long term and emphasizing lower profits due to higher entry costs early in the game. Our analysis also calls for more careful analysis 
when designing policies aiming at the economy-wide adoption of new technologies.

It is important to note that our contribution goes beyond the documentation of strategic entry in the U.S. market for drive-in theaters. First, we emphasize the need for an exogenous measure of market size when studying strategic entry. In our particular case, we use weather as a driver of the number of days that a drive-in theater may operate within a year. More generally, we warn researchers and policy makers of the peril associated with using crosssectional differences in population or sales as good indicators of differences in market size. Second, our reduced-form methodology presents a straightforward empirical strategy to test for the existence of non-monotonicity of market size and early entry. Third, our structural estimation provides a clear benchmark to quantify the impact of entry deterrence strategies in scenarios when early entry is driven by strategic motives allowing for future improvements on policy and antitrust evaluation. Fourth and finally, our analysis clearly shows the link between counterfactual results and thereduced-form relationship between market-size and the technology diffusion process.

Our hope is that future research builds on our work here, and furthers our understanding of how strategic behavior shapes widely accepted facts of industry structure and adoption of new technologies. When pursuing such an ambitious goal, we believe that research should aim to study how the distribution of prices, quantities, capacity or R\&D investments change with market size with and without strategic entry. By doing so, we are likely to improve both policy design and our understanding of strategic investments. 


\section{References}

Victor Aguirregabiria and Pedro Mira. Sequential estimation of dynamic discrete games. Econometrica, 75(1):1-53, 2007.

C. Lanier Benkard. A dynamic analysis of the market for wide-bodied commercial aircraft. The Review of Economic Studies, 71(3):581-611, 2004.

B. Douglas Bernheim. Strategic deterrence of sequential entry into an industry. The RAND Journal of Economics, 15(1):1-11, 1984.

Jeremy Bulow, John Geanakoplos, and Paul Klemperer. Holding idle capacity to deter entry. The Economic Journal, 95(377):178-182, 1985.

Joan Calzada and Tommaso M Valletti. Network competition and entry deterrence. The Economic Journal, 118(531):1223-1244, 2008.

Myong-Hun Chang. Flexible manufacturing, uncertain consumer tastes, and strategic entry deterrence. The Journal of Industrial Economics, pages 77-90, 1993.

Judith A. Chevalier. Do lbo supermarkets charge more? an empirical analysis of the effects of lbos on supermarket pricing. Journal of Finance, 50(4):1095-1112, 1995.

Ronald W Cotterill and Lawrence E Haller. Barrier and queue effects: A study of leading us supermarket chain entry patterns. The Journal of Industrial Economics, pages 427-440, 1992.

Leemore S Dafny. Games hospitals play: Entry deterrence in hospital procedure markets. Journal of Economics \& Management Strategy, 14(3):513-542, 2005.

Ulrich Doraszelski and Kenneth L Judd. Avoiding the curse of dimensionality in dynamic stochastic games. Quantitative Economics, 3(1):53-93, 2012.

Ulrich Doraszelski and Mark Satterthwaite. Computable markov-perfect industry dynamics. The RAND Journal of Economics, 41(2):215-243, 2010.

Glenn Ellison and Sara Fisher Ellison. Strategic entry deterrence and the behavior of pharmaceutical incumbents prior to patent expiration. American Economic Journal: Microeconomics, 3(1):1-36, 2011.

Limin Fang and Nathan Yang. Measuring preemptive entry in dynamic oligopoly games. Working Paper, 2021.

Drew Fudenberg and Jean Tirole. Preemption and rent equalization in the adoption of new technology. The Review of Economic Studies, 52(3):383-401, 1985.

Drew Fudenberg and Jean Tirole. Pricing a network good to deter entry. Journal of Industrial Economics, 48(4):373-390, 2003.

Ricard Gil. Does vertical integration decrease prices? evidence from the paramount antitrust case of 1948. American Economic Journal: Economic Policy, 7(2):162-191, 2015.

Ricard Gil and Myongjin Kim. Does competition increase quality? evidence from the us airline industry. International Journal of Industrial Organization, 77:102742, 2021.

Richard Gilbert and Xavier Vives. Entry deterrence and the free rider problem. The Review of Economic Studies, 53(1):71-83, 1986. 
Avi Goldfarb and Mo Xiao. Who thinks about the competition? managerial ability and strategic entry in us local telephone markets *. The American Economic Review, 101(7): 3130-3161, 2011.

Austan Goolsbee Goolsbee and Chad Syverson Syverson. How do incumbents respond to the threat of entry? evidence from the major airlines. Quarterly Journal of Economics, 123(4): 1611-1633, 2008.

Paul Hünermund, Philipp Schmidt-Dengler, and Yuya Takahashi. Entry and shakeout in dynamic oligopoly. Research Papers in Economics, 2014.

Mitsuru Igami and Nathan Yang. Unobserved heterogeneity in dynamic games: Cannibalization and preemptive entry of hamburger chains in canada. Quantitative Economics, 7(2): $483-521,2016$.

Marvin B. Lieberman. The learning curve, diffusion, and competitive strategy. Strategic Management Journal, 8(5):441-452, 1987.

Martin Pesendorfer and Philipp Schmidt-Dengler. Asymptotic least squares estimators for dynamic games. The Review of Economic Studies, 75(3):901-928, 2008.

John Rust. Optimal replacement of gmc bus engines: An empirical model of harold zurcher. Econometrica: Journal of the Econometric Society, pages 999-1033, 1987.

Steven C Salop. Strategic entry deterrence. The American Economic Review, 69(2):335-338, 1979 .

Richard Schmalensee. Advertising and entry deterrence: an exploratory model. Journal of political Economy, 91(4):636-653, 1983.

Philipp Schmidt-Dengler. The timing of new technology adoption: The case of mri. Research Papers in Economics, 2006.

Robert C. Seamans. Fighting city hall: Entry deterrence and technology upgrades in cable tv markets. Management Science, 58(3):461-475, 2012.

Yuya Takahashi. Estimating a war of attrition: The case of the us movie theater industry. The American Economic Review, 105(7):2204-2241, 2015.

Michael Waldman. Noncooperative entry deterrence, uncertainty, and the free rider problem. The Review of Economic Studies, 54(2):301-310, 1987.

Douglas S. West. Testing for market preemption using sequential location data: Reply. The Bell Journal of Economics, 12(1):129-143, 1981. 


\section{Appendix A. Details of the Simple Model}

There are two periods $t=1,2$ and two potential entrants. We solve the game by backward induction. In period $t=T=2$, the expected payoff of each player varies according to the value of $n_{i, t}$. If $n_{i, t}=2$, each player's expected payoff is

$$
W_{i, t}(2)=\frac{\pi_{i, t}(2)}{1-\delta}
$$

If $n_{i, t}=1$, the incumbent's expected value function is

$$
W_{i, t}^{\sigma}(1)=\sigma W_{i, t}(2)+(1-\sigma) \frac{\pi_{i, t}(1)}{1-\delta} .
$$

The potential entrant's expected value function is

$$
\begin{aligned}
V_{i, t}(1) & =E_{\epsilon}\left[\max \left\{V_{i, T}\left(0, n_{i, t}\right)+\epsilon_{i T 0}, V_{i, T}\left(1, n_{i, t}\right)-F_{i}-\gamma_{t}^{0}+\epsilon_{i T, 1}\right\}\right] \\
& =\gamma+\ln \left(1+\exp \left(\frac{\pi_{i, t}(2)}{1-\delta}\right)\right)
\end{aligned}
$$

and the conditional choice probability is

$$
\sigma_{i, t}^{*}(1)=\operatorname{Pr}\left(a_{i, t}(1)=1\right)=\frac{\exp \left(V_{i, T}\left(1, n_{i, t}\right)\right)}{1+\exp \left(V_{i, T}\left(1, n_{i, t}\right)\right)} .
$$

If $n_{i, t}=0$, each potential entrant's expected profit function is

$$
\bar{\pi}_{i, t}^{\sigma}\left(a, s_{i, t}\right)= \begin{cases}\sigma \pi_{i, t}(2)+(1-\sigma) \pi_{i, t}(1) & a=1 \\ 0 & a=0\end{cases}
$$

The conditional choice probability is

$$
\sigma_{i, t}^{*}(0)=\operatorname{Pr}\left(a_{i, t}(0)=1\right)=\frac{\exp \left\{\frac{1}{1-\delta} \bar{\pi}_{i, t}^{\sigma}\left(1, s_{i, t}\right)\right\}}{1+\exp \left\{\frac{1}{1-\delta} \bar{\pi}_{i, t}^{\sigma}\left(1, s_{i, t}\right)\right\}} .
$$

The consistency between beliefs and strategies requires $\sigma=\sigma_{i, t}^{*}(0)$.

In period $t=1, n_{i 0} \equiv 0$. The choice-specific value functions are

$$
\begin{aligned}
& V_{i 1}^{\sigma}\left(1, n_{i 1}\right)=\sigma\left(\pi_{i 1}(2)+\delta W_{i, t}(2)\right)+(1-\sigma)\left(\pi_{i 1}(1)-F_{i}-\gamma_{1}^{t}+W_{i, t}(1)\right) \\
& V_{i 1}^{\sigma}\left(0, n_{i 1}\right)=\delta\left(\sigma V_{i, t}(2)+(1-\sigma) V_{i, t}(1)\right)
\end{aligned}
$$

The conditional choice probability is

$$
\sigma_{i, 1}^{*}(0)=\frac{\exp \left(V_{i, 1}^{\sigma}\left(1, n_{i, 1}\right)\right)}{\exp \left(V_{i, 1}^{\sigma}\left(0, n_{i, 1}\right)\right)+\exp \left(V_{i, 1}^{\sigma}\left(1, n_{i, 1}\right)\right)}
$$

The consistency between beliefs and strategies requires $\sigma=\sigma_{i 1}^{*}(0)$.

The Markov Perfect Equilibria can then be characterized by the fixed point $\left(\sigma_{i, t}^{*}(0), \sigma_{i, t}^{*}(1), \sigma_{i 1}^{*}(0)\right)$ (i.e., Equations (17), (18), and (19)) and the corresponding value functions. 


\section{Appendix B. Details on the Counterfactual Analysis}

\section{B.1. Distribution of the number of incumbents in the commitment equilibrium}

In this section, we first derive the beliefs of a potential entrant on the number of incumbents at the beginning of period $t, Q_{i, t}^{\sigma}\left(n_{i, t}\right)$. It is equal to $\operatorname{Pr}\left(n_{i, t}=n \mid n_{i, 1}=0\right)$, the probability of having $n_{i, t}$ rivals entering before period $t$ conditional on $n_{i, 1}=0$. Using the Law of Total Probability, we can calculate the transition probability $\operatorname{Pr}\left(n_{i, t} \mid n_{i, 1}=0\right)$ recursively,

$$
\begin{aligned}
\operatorname{Pr}\left(n_{i, 3} \mid n_{i, 1}\right) & =\sum_{n_{i, 2} \leq n_{i, 3}} \operatorname{Pr}\left(n_{i, 3} \mid n_{i, 2}\right) \operatorname{Pr}\left(n_{i, 2} \mid n_{i, 1}\right), \\
\cdots & \\
\operatorname{Pr}\left(n_{i, t} \mid n_{i, 1}\right) & =\sum_{n_{i, t-1} \leq n_{i, t}} \operatorname{Pr}\left(n_{i, t} \mid n_{i, t-1}\right) \operatorname{Pr}\left(n_{i, t-1} \mid n_{i, 1}\right), t \leq T
\end{aligned}
$$

where $\operatorname{Pr}\left(n_{i, t} \mid n_{i, t-1}\right)=\mathrm{B}\left(N-1-n_{i, t-1}, n_{i, t}-n_{i, t-1}, \sigma_{i, t-1}^{*}\right)$ is the probability of $n_{i, t}-n_{i, t-1}$ out of $N-1-n_{i, t-1}$ potential entrants entering in period $t-1$ following their strategy $\sigma_{i, t-1}^{*}$.

\section{B.2. Simulation algorithm}

1. Use equilibrium in the baseline model $\sigma^{0}=\sigma_{i, t}\left(n_{i, t}\right)$ as an initial guess of commitment equilibrium, where $n_{i, t}$ is data.

2. Given the initial guess, calculate the transition probabilities perceived by incumbents and entrants (equations (6) and (7)) and a potential entrant's belief of the number of incumbents at the beginning of each period $Q_{i, t}^{\sigma}\left(n_{i, t}\right)$ (equation (20)).

3. Solve the model backward and get best response $\sigma_{i, t}^{*}$.

4. Repeat until $\sigma^{0}$ and $\sigma_{i, t}^{*}$ converge.

\section{B.3. An Illustrative Example}

Consider a simplified version of the model where there are 2 potential entrants and 2 periods. The parametric setups are summarized in Table 1.

Table 1: Parametric setups

\begin{tabular}{l|c|c}
\hline \hline & Parameter & Value \\
\hline Basics & $T$ & \\
Number of periods & $N$ & 2 \\
Number of potential entrants & $\delta$ & 0.9 \\
Discount factor & & \\
Profit function & $\theta$ & 2 \\
Implied competition (à la Cournot) & $M_{i}$ & $\mathrm{U}[0,1]$ \\
Market size & $y_{i, t}$ & $5+2 \log t$ \\
Willingness-to-pay & $F_{i, t}$ & $5-2 \log t$ \\
Entry cost
\end{tabular}


Figure 1: Comparative Statics

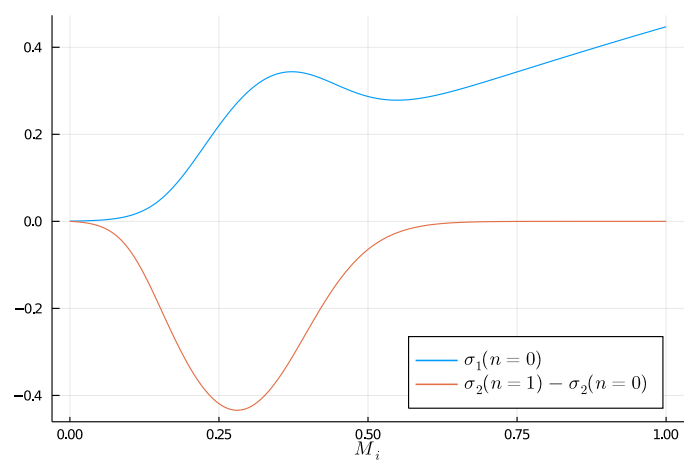

(a) Market Size and Entry Probabilities

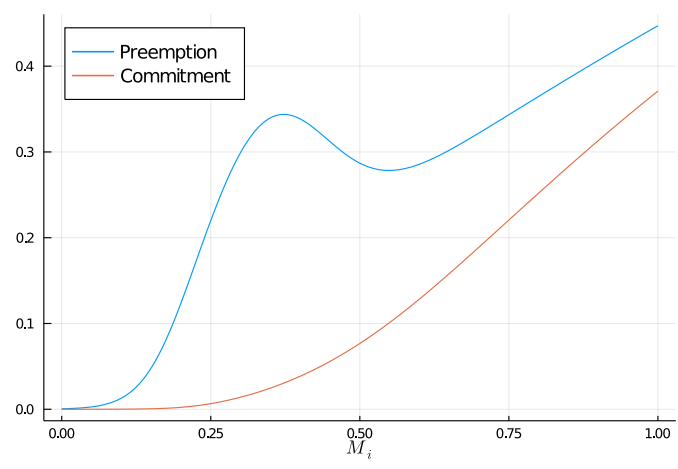

(b) MPE \& Commitment Equilibrium

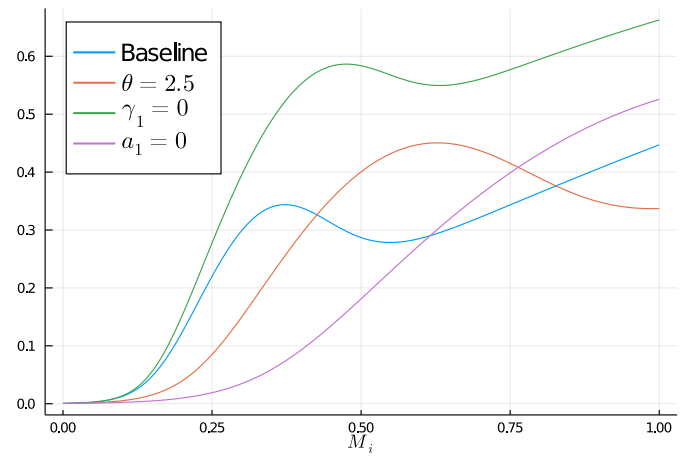

(c) First-Period Entry Probability

Notes: Figure 2(a) shows, for each market size, the entry probability in the first period and reduction in second-period entry probability if a market is occupied by one firm. Figure 2(b) depicts the first-period entry probabilities in the Markov perfect equilibrium and the commitment equilibrium, respectively. Figure 2(c) illustrates how first-period entry probability varies with market size and parameters.

Figure 2(a) shows, for each market size, the entry probability in the first period and reduction in the second-period entry probability if a market is occupied by one firm. The first (blue) line shows that first-period entry probability is non-monotonic in market size. The second (orange) line suggests that entry deterrence is largest for medium-size markets.

Figure 2(b) depicts the first-period entry probabilities in the Markov perfect equilibrium and the commitment equilibrium, respectively. Under commitment equilibrium, the firstperiod entry probability is monotonically increasing with market size. All else equal, a firm is more likely to enter in the first period if variable profit is higher to compensate for the sunk entry cost. Under Markov perfect equilibrium, a firm's strategy is more than just comparing variable profit and sunk entry cost - it can deter rivals' entry in the second period by entering early. Therefore, the first-period entry probability is higher under MPE than under commitment equilibrium at any given market size. Consistent with Figure 2(a), the difference in entry probability under the two equilibrium concepts is larger for medium size markets.

Figure 2(c) illustrates a sequence of comparative statics. First, when competition implied by the profit function is greater ( $\theta$ increases from 2 to 2.5) or consumer willingness-to-pay does not grow over time $\left(a_{1}=0\right)$, the preemptive motive becomes lower for small markets and higher for medium and large markets. Moreover, when entry cost does not decline over time, the preemptive motive increase for almost all market sizes. 